\title{
Formic acid: A versatile renewable reagent for green and sustainable chemical synthesis
}

\author{
Xiang Liu †, Shushuang Li ${ }^{\dagger}$, Yongmei Liu, Yong Cao* \\ Shanghai Key Laboratory of Molecular Catalysis and Innovative Materials, Department of Chemistry, Fudan University, Shanghai 200433, China
}

\section{A R T I C L E I N F O}

Article history:

Received 2 March 2015

Accepted 4 April 2015

Published 20 September 2015

\section{Keywords:}

Formic acid

Innovative catalysis

Renewable hydrogen source

Benign feedstock

Chemical synthesis

Biomass valorization

\begin{abstract}
A B S T R A C T
Formic acid is available as a major byproduct from biorefinery processing and this together with its unique properties, including non-toxicity, favorable energy density, and biodegradability, make it an economically appealing and safe reagent for energy storage and chemical synthesis. This review provides an overview of novel recent achievements in green catalytic transformations that use biogenic formic acid as an efficient and versatile reagent. The examples selected demonstrate the advantages of formic acid in addressing the key issues (minimizing the use and generation of hazardous substances while maximizing productivity under mild and benign reaction conditions) in clean chemical transformation. Special emphasis is put on the prospects of formic acid for delivering new catalytic technology to produce a plethora of tailor-made products via the flexible and selective conversion of renewable biomass resources. The potential of formic acid as a renewable $\mathrm{C}_{1}$ feedstock for both bulk and fine chemical syntheses is also outlined with examples. The role of multifunctionality in catalyst design as a key aspect in developing new catalytic concepts capable of promoting new transformations to give unprecedented selectivity and efficiency is also discussed. This article is expected to advance research on sustainable, green and affordable bio-based processes as alternatives to traditional ones with the goal to develop a fully sustainable chemical industry based on renewable resources.
\end{abstract}

(C) 2015, Dalian Institute of Chemical Physics, Chinese Academy of Sciences. Published by Elsevier B.V. All rights reserved.

\section{Introduction}

The search for sustainable chemical processes has never been more important than it is today in light of current dwindling nonrenewable energy resources such as petroleum and, more importantly, their unabated negative environmental impacts. For this purpose, the exploration of new strategies to develop catalytic methods that work under ambient conditions, maximize atom utilization, and directly transform natural resources, such as renewable biomass, into useful chemical products is highly desirable [1]. A major challenge to the transition from petroleum-based feedstocks to biorenewable resources is the effective deoxygenation of bio-molecules. To this end, reactions involving biogenic carboxylic acids, in particular, formic acid ( $\mathrm{HCOOH}, \mathrm{FA})$, have been identified as important reactions for the conversion of biomass feedstocks to hydrogen, chemicals, and fuel grade alkanes [1]. The most attractive features of FA, apart from its accessibility as a major byproduct from lignocellulosic biomass processing, are efficient $\mathrm{H}_{2}$ production by selective FA decomposition (Scheme 1(a)) and the

\footnotetext{
* Corresponding author. Tel : +86-21-55665287 ; Fax: +86-21-65643774; E-mail: yongcao@fudan.edu.cn

† These authors contributed equally to this work

This work was supported by the National Natural Science Foundation of China (21273044, 21473035), the Research Fund for the Doctoral Program of Higher Education (20120071110011) and Science \& Technology Commission of Shanghai Municipality (08DZ2270500, 12ZR1401500). DOI: 10.1016/S1872-2067(15)60861-0 | http://www.sciencedirect.com/science/journal/18722067 | Chin. J. Catal., Vol. 36, No. 9, September 2015
} 


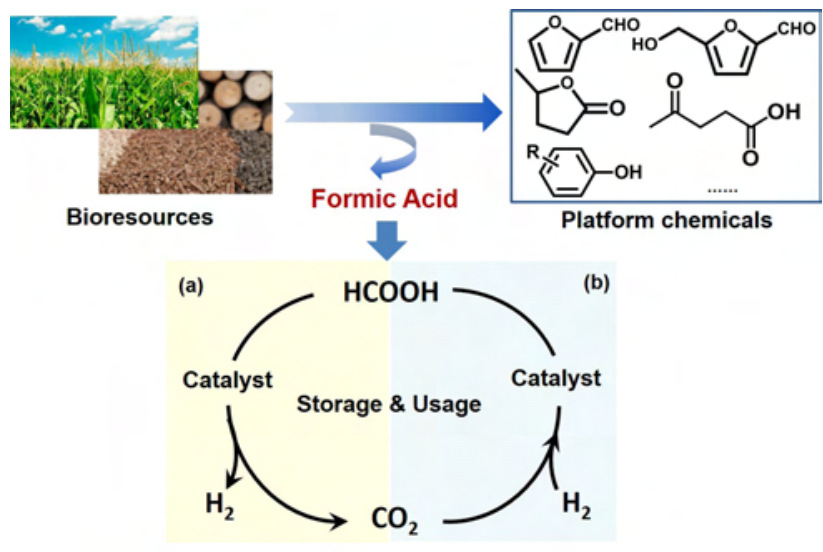

Scheme 1. FA production in biorefineries and its utilization in a $\mathrm{H}_{2}$-energy storage system.

possibility of the direct formation of $\mathrm{CO}$-free clean $\mathrm{H}_{2}$ that cannot be produced from other substrates under practical and convenient conditions [2]. Given its non-toxicity and high energy density (far exceeding that of most other $\mathrm{H}_{2}$ storage materials used today), $\mathrm{FA}$ is an ideal $\mathrm{H}_{2}$ storage material with enormous potential to meet the power needs of small fuel cells for portable applications [2]. A major research endeavor in FA chemistry is finding a suitable catalytic material that can facilitate effective and controlled $\mathrm{H}_{2}$ evolution under ambient conditions, which is possibly a critical step to establish a "carbon-neutral" $\mathrm{H}_{2}$-energy storage system (Scheme 1(b)) based on reversible $\mathrm{FA}-\mathrm{CO}_{2}$ interconversion [2].

Aside from the above incentives, there is an additional interest to use FA as a bio-renewable feedstock for chemical synthesis with the aim to develop new enabling catalytic technologies based on renewable resources. In this connection, fundamental advances in the catalysis of selective FA decomposition have promoted the search for new efficient and selective reductive transformations to replace conventional catalytic hydrogenation processes [3-6]. This is largely driven by the fact that $\mathrm{H}_{2}$ gas currently derived from non-renewable natural gas or petroleum is highly explosive, thus, posing significant safety concerns and the need for alternative safer and more effective technologies [7]. Whereas current efforts mainly involve the use of liquid FA as a convenient hydrogen source for green

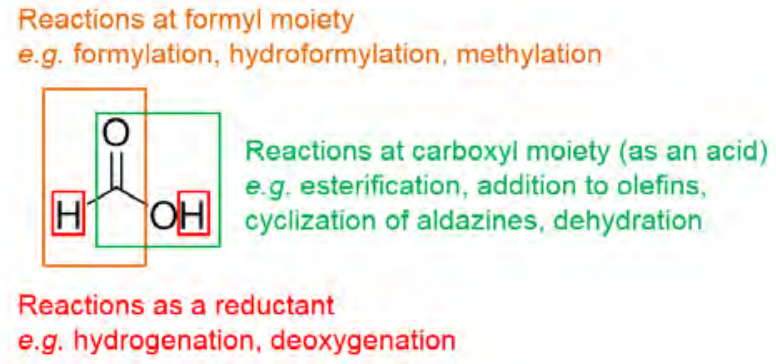

Scheme 2. Reactivity portrait of FA.

organic synthesis, the true potential offered by FA for efficient and selective transformations, especially toward the conversion of biogenic feedstocks, has been recognized only very recently. Scheme 2 exemplifies a diverse range of highly attractive products and building blocks that can be derived from FA [8]. Due to its reactive carbonyl and hydroxyl functionalities, FA has many kinds of reactions, including esterification, dehydration, formylation, addition to olefins, and cyclization of toluene diamines. Of further interest is that sequences of the relevant reactions such as tandem reduction-formylation, addition-amination, cascade esterification-dehydroxylation, etc., can led to the direct "one-pot" construction of diverse, interesting, and complex structures from readily available starting materials. A key prerequisite for such advanced synthetic concepts lies in the development of new versatile catalytic approaches for flexible and controlled FA activation.

In this review, we describe recent progress in the synthetic transformations enabled by catalytic FA activation using selected examples from the literature and our own research. Although the investigation of FA as a suitable liquid medium for cleaner $\mathrm{H}_{2}$ production and as a hydrogen storage material has been extensively reviewed [2], no review has been devoted to a discussion of the synthetic potentials offered by FA in the context of sustainable green catalysis since the classical review in 1969 covering the chemistry of FA and its simple derivatives [8]. This review will demonstrate that in many cases FA-mediated catalytic reaction systems are advantageous for better efficiency or even give previously unknown reaction routes as the basis of new sustainable chemical technologies. In

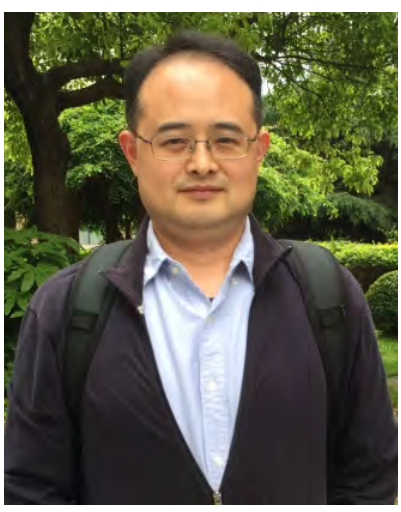

Yong Cao (Department of Chemistry, Fudan University) received the Catalysis Award for Young Scientists (for his creative achievements in the field of heterogeneous gold catalysis) in 2014, which was presented by The Catalysis Society of China. Professor Yong Cao received his Ph.D. degree in Physical Chemistry from Department of Chemistry, Fudan University, in 2000, and he joined the same University and was promoted to full professor in 2005. He is presently on the editorial board of Applied Catalysis A-General, Chinese Journal of Catalysis, and Acta Physico-Chimica Sinica. His research program includes the development of new synthetic methods and novel heterogeneous metal catalysts, catalytic conversion of biomass into chemicals and biofuels, new strategy and new material for renewable hydrogen production and storage, chemical utilization of natural gas and related feedstocks, surface and interfacial chemistry. More broadly, his research interests focus on the development of fundamental chemistry of heterogeneous catalysis and implementation of green and sustainable chemistry and related technologies into new products and processes. He has published more than 160 peer-reviewed papers with over 3000 citations. 
order to highlight future opportunities, emphasis is placed on understanding the key catalytic aspects in developing FA-mediated transformation strategies for the conversion of abundantly available feedstocks, with special attention to FA as a benign $\mathrm{C}_{1}$ feedstock. Emphasis is also put on the selective transformation of biomass and biomass related model compounds by FA catalysis, which may give new attractive biorefinery strategies. The attractiveness of FA as a green solvent for organic synthesis and biomass valorization is also discussed.

\section{A historical overview of the chemo-catalytic aspects of FA}

In general, FA is an environmentally acceptable and highly efficient organic acid. Noticeably different from mineral acids is that FA evaporates without leaving any residue. Due to its acidity, its aldehyde nature, and its reducing properties, FA is used in a variety of fields ranging from leather processing to feed preservation. In contrast to the rich chemistry already established by the organic community, efforts to explore the catalytic aspects of FA have only focused primarily on selective $\mathrm{H}_{2}$ production by FA decomposition [2]. The history behind catalytic FA decomposition dates back to the pioneering work of Sabatier et al., who identified that the decomposition of FA occur by two reaction pathways, namely, decarboxylation yielding $\mathrm{H}_{2}$ and $\mathrm{CO}_{2}$ and dehydration into $\mathrm{CO}$ and $\mathrm{H}_{2} \mathrm{O}$ (Scheme 3) [9]. Since then, FA has been utilized as a probe molecule for heterogeneous reactions on metals, metal oxides, metal carbides, and oxide-supported metals. Researchers employing theoretical and computational methods have also investigated FA as a molecule to probe reactivity [7]. From the standpoint of catalysis, especially interesting is that the selectivity of the two possible pathways can be controlled by the choice of catalyst. Moreover, the parallel pathways in Scheme 3 are connected by the water-gas shift (WGS) reaction, which is important in several industrial catalytic technologies such as ammonia synthesis, methanol synthesis, and Fischer-Tropsch processes [7]. The classic "volcano curve" (Fig. 1) [7] derived from the study on FA decomposition over metallic powders has been particularly valuable in shaping our current understanding of heterogeneous catalysis [7].

In the past decade, the use of FA as an alternative hydrogen or carbon source has seen renewed and increasing interest as FA has been identified as the most common and important byproduct of the biorefineries (Scheme 1) and bio-based industrial technologies [1]. The efficient and effective utilization of FA can play an important role in building resilient supply chains for a future economy as FA can serve as an energy carrier and a flexible non-petroleum feedstock that enables safe

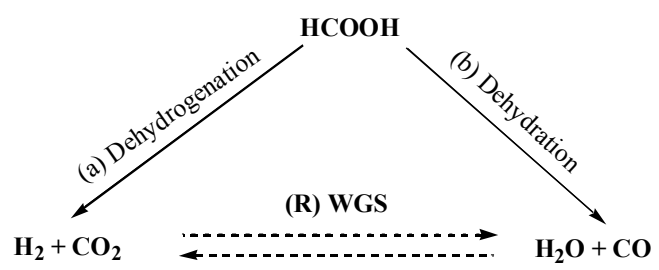

Scheme 3. Reaction pathways for the decomposition of FA [9].

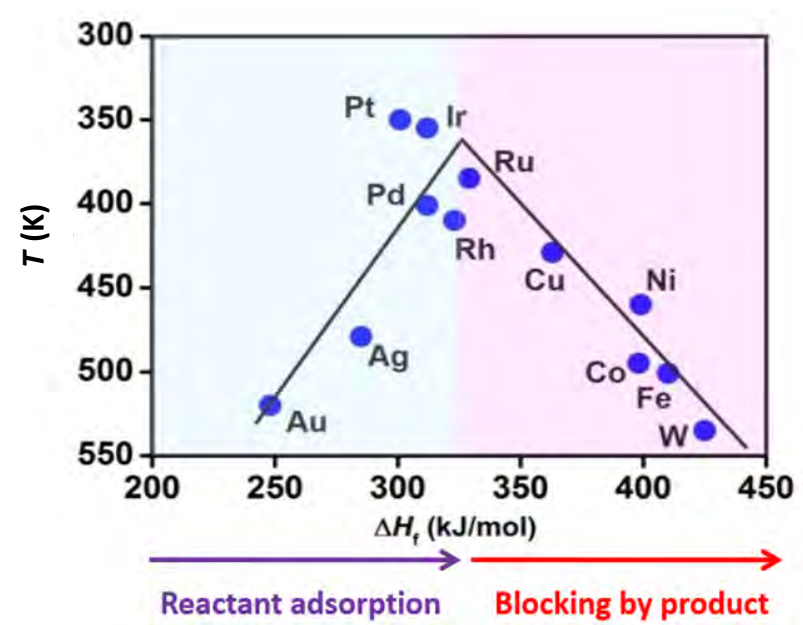

Fig. 1. Volcano plot for the decomposition of FA on transition metals [7].

production with exceptional versatility. Another stimulus is the concept to use FA as a liquid organic hydrogen carrier to address the supply challenge associated with fuel cell technology [2]. This has prompted endeavors directed toward the selective decomposition of liquid phase FA where the production of CO-free $\mathrm{H}_{2}$ at convenient temperatures is of great importance. Along with fundamental advances on the hydrogenation of $\mathrm{CO}_{2}$ to FA at moderate temperatures and high pressures, this gives a good entry point to use cheap, non-toxic $\mathrm{CO}_{2}$ as a renewable and eco-friendly $\mathrm{C}_{1}$ source for the synthesis of value added chemicals or fuels, and also has the promise to establish an integrated energy storage scheme for a dispatchable solar and wind powered energy system. In the last five years, reactions involving FA have experienced rapid growth. Recent applications of the homogeneous and heterogeneous catalytic behavior of metal-based compounds or related materials have also given many new challenging directions motivated by industrial demands.

\section{FA-mediated selective functional group transfor- mations}

The ultimate goal in synthetic organic chemistry is to achieve the ideal synthesis in terms of activity, selectivity, as well as atom and step economy. For this objective, the developing of more sustainable catalytic processes that reduce wastes together with the use of renewable feedstocks, eco-friendly reagents and catalysts remain highly urgent. The employment of renewable, clean and relatively safe regents, such as the versatile biogenic FA, provides a potential route to this goal. In this section, we focus on the recent achievements in several types of FA-mediated selective functional group transformations with FA as a reductive agent or $\mathrm{C}_{1}$ building block. We highlight some examples of catalytic reduction of specific functional groups that use FA as an efficient hydrogen source, such as the hydrogenation of carbonyl compounds to alcohols, imines, nitriles or nitros to amines, alkynes to alkenes, and alkenes to alkanes as well as the hydrogenolysis of alcohols or epoxides. A detailed discussion of appealing tandem reactions 
for the production of value added fine chemicals with the use of FA as a benign synthon is also described. These reactions include direct reductive $\mathrm{N}$-formylation of quinoline derivatives, $\mathrm{N}$-formylation and methylation of amines, carbonylation of olefins, and reductive hydration of alkynes. We also emphasize a novel transformation of FA, very recently demonstrated in the literature $[10,11]$, that methanol can be efficiently and selectively produced through a catalytic disproportionation of FA.

\subsection{Reduction of specific functional groups}

Regarding the reduction of chemical substances using FA as a green hydrogen donor, the most studied reaction is the selective conversion of carbonyl functionalities to the corresponding alcohols of synthetic and biological interest. In the past decade, efforts have been invested in the investigation of FA-mediated asymmetric transfer hydrogenation of ketones to chiral alcohols using organometallic compounds, such as $\mathrm{Ru}$ [12], $\mathrm{Rh}$ [12], Ir [13], and Fe [14] complexes. As a consequence of the increasing demand for greener laboratory and practical industrial applications, the development of chiral catalysts covalently attached to an insoluble support has created fast growing interest. Research efforts have been devoted to the preparation of immobilized homogeneous catalysts, esp. Ru complexes, on a variety of different polymeric organic and inorganic supports for the FA-mediated chemo- and stereo- selective reduction of $\mathrm{C}=0$ groups, sometimes in the presence of other reducible functional groups such as $\mathrm{C}=\mathrm{C}$ [15-17]. For instance, the chemoselective hydrogenation of $\alpha, \beta$-unsaturated aldehydes with FA to allylic alcohols was successfully promoted by a recoverable polymer-bound Rh complex catalyst [15]. While this heterogenized catalyst has some advantages over the traditional homogenous ones in terms of ease of catalyst and product separation, its tedious preparation and catalyst recyclability remain far from satisfactory. Yu et al. [18] developed a more "user-friendly" protocol comprising catalytic $\mathrm{Pd}(0)$ clusters encapsulated in polyurea ([Pd0En-Cat $]$ ) for the chemoselective hydrogenation of a wide range of aryl ketones to benzyl alcohols with FA as hydrogen source (Scheme 4). Although this polymer-based supported Pd catalyst offers simple procedures for catalyst-product separation and recovery, a catalyst supported on a solid oxide surface is more desirable from a practical point of view.

The preparation of amines, the key intermediates for the production of pharmaceuticals, dyes and ligands for transition metal-catalyzed reactions, can also use the FA-mediated catalytic reduction of imines, nitriles and nitro compounds. As a matter of fact, the chiral Ru complex systems employed for the above asymmetric saturation $\mathrm{C}=0$ linkages have often been applied for the asymmetric reduction of $\mathrm{C}=\mathrm{N}$ group [15-17]. In

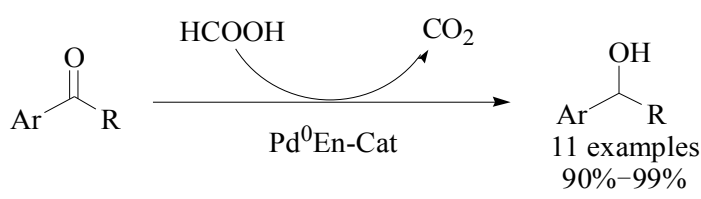

Scheme 4. $\left[\mathrm{Pd}^{0} \mathrm{En}-\mathrm{Cat}\right]$-catalyzed hydrogenation of aryl ketones to benzyl alcohols [18].

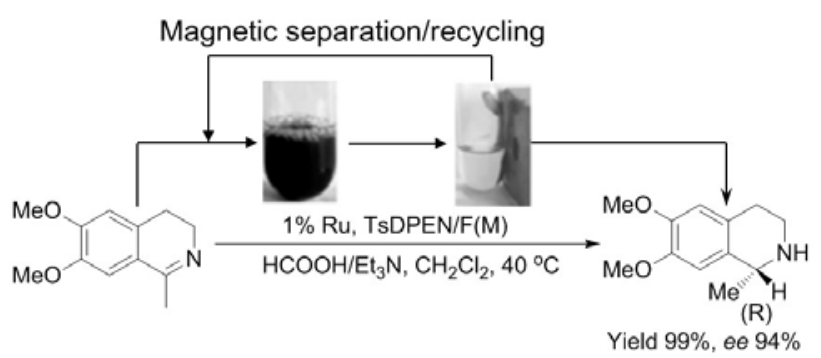

Scheme 5. Asymmetric transfer hydrogenation of imine in $\mathrm{Ru}-\mathrm{TsDPEN}-\mathrm{HCOOH}-\mathrm{Et}_{3} \mathrm{~N}$ system [17].

2009, Li et al. [17] developed a magnetic siliceous mesocellular foam immobilized ruthenium complex (Ru-TsDPEN; TsDPEN $=N$ - $(p$-toluenesulfonyl)-1,2-diphenylethylenediamine $)$ catalyst. This heterogeneous Ru catalyst exhibited high catalytic activity and good enantioselectivity in the asymmetric transfer hydrogenation of imine in the $\mathrm{HCOOH}-\mathrm{Et}_{3} \mathrm{~N}$ system (Scheme 5). It could be easily reused for at least nine runs with a slight ee decrease from $94 \%$ to $90 \%$. In the case of FA-mediated nitrile hydrogenation, Beller's group [19] demonstrated a simple catalytic reduction system for the transfer hydrogenation of (hetero)aryl nitriles to the corresponding primary amines with HCOOH-NEt 3 . In the presence of commercially available $\mathrm{Pd} / \mathrm{C}$ (10 wt $\% \mathrm{Pd})$, the straightforward and selective reduction could be smoothly achieved without any additive under mild conditions $\left(40^{\circ} \mathrm{C}\right.$ or r.t.). In the chemoselective reduction of nitro compounds with FA, various heterogeneous catalysts, such as Pd supported on carbon [20], alginate/ionic liquid highly porous monoliths [21] or zirconium phosphate [22], have been successfully prepared and used in amine production. Beller's group [23] recently demonstrated that a cobalt oxide based nanomaterial $\left(\mathrm{Co}_{3} \mathrm{O}_{4}-\mathrm{NGr} @ \mathrm{C}, 2 \mathrm{~mol} \% \mathrm{Co}\right)$ prepared by the pyrolysis of cobalt-phenanthroline complexes-impregnated carbon is a highly selective catalyst for the transfer hydrogenation of nitroarenes using FA as hydrogen source (yield up to $97 \%$, Scheme 6). This non-noble metal material performed excellently in the reduction of many structurally diverse and functionalized nitroarenes with unprecedented chemoselectivity and with halide, olefin, aldehyde, ketone, ester, amide and nitrile functionalities.

Besides alcohol and amine production, the FA-mediated reduction systems can also be applied to the hydrogenation of double or triple carbon-carbon bonds. The selective catalytic hydrogenation of $\mathrm{C} \equiv \mathrm{C}$ bonds, particularly to $\mathrm{C}=\mathrm{C}$ bonds, has been the subject of numerous investigations due to its synthetic utility and also for the selectivity of metal catalysts for the semihydrogenation [3]. Though several heterogeneous catalytic protocols with $\mathrm{H}_{2}, \mathrm{CO} / \mathrm{H}_{2} \mathrm{O}$, trialkylammonium formate, 1,4-dihydropyridine, and organo-silanes as hydrogen sources
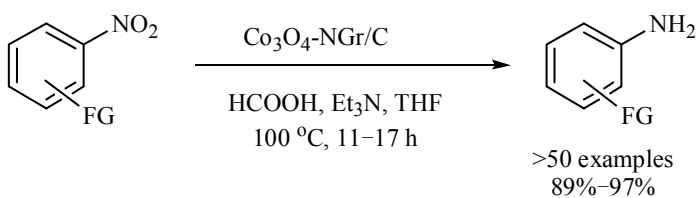

Scheme 6. $\mathrm{Co}_{3} \mathrm{O}_{4}-\mathrm{NGr} @ \mathrm{C}$-catalyzed hydrogenation of nitroarenes using FA [23]. 
have been reported [3], those using FA as a safer and more expedient hydrogen donor are surprisingly quite limited. The first example was reported by Yu [24] in 1998, in which the mechanism of Pd/C-catalyzed transfer hydrogenation of phenylpropiolate to cis-alkene with FA was investigated. The corresponding D-labeling studies proved that palladium diformate is a key intermediate in this transformation. Wagh et al. [25] recently developed an excellent unsupported nanoporous gold-catalyzed transfer reduction strategy for chemo- and stereoselective semihydrogenation of alkynes to $Z$-olefins with one equivalent of FA. The system provides a facile method for the semihydrogenation of a broad range terminal/internal and aromatic/aliphatic alkynes with good functional group tolerance. In addition to the semihydrogenation of $\mathrm{C} \equiv \mathrm{C}$ bond by $\mathrm{FA}$, the FA-mediated selective reduction of the $\mathrm{C}=\mathrm{C}$ bond was also achieved. In parallel to the vapor phase hydrogenation of ethylene and propylene over $\mathrm{Pd} / \mathrm{C}$ with FA at relatively low temperatures $\left(<167^{\circ} \mathrm{C}\right)[26]$, Li's group [27] recently found that a Mott-Schottky type catalyst based on $\mathrm{g}-\mathrm{C}_{3} \mathrm{~N}_{4}$ supported $\mathrm{Pd}$ nanoparticles $(\mathrm{Pd} / \mathrm{CN})$ showed high activity for the hydrogenation of various olefins and bio-derived 2-methylfuran at $25{ }^{\circ} \mathrm{C}$ (yield up to 99\%). All the reactions were conducted in an aqueous solution of FA under ambient atmosphere and the catalyst can be reused at least 26 times while maintaining a high 2-methyl-tetrahydrofuran yield over 99\% (Fig. 2).

\subsection{Hydrogenolysis and deprotection}

Catalytic hydrogenolysis involving the reductive cleavage of sigma bonds, such as $\mathrm{C}-\mathrm{O}, \mathrm{C}-\mathrm{N}, \mathrm{C}-\mathrm{S}$, and $\mathrm{C}-\mathrm{X}$ bonds, is a very important technology widely applied in organic synthesis, water conservation and the petroleum industry. Several recent studies have demonstrated that the hydrogenolysis of the $\mathrm{C}-\mathrm{O}$ bonds in epoxides and saturated alcohols can be achieved with FA [3]. In general, epoxides are labile to hydrogenolysis under rather mild conditions because of a strong tendency to release their ring strain. Shimizu et al. [28] observed that both regioand stereoselectivity of the hydrogenolysis of (E)-4,5-epoxy-4-methyl-2-alkenoates were successful to afford (E)-5-hydroxy-4-methyl-2-alkenoates, a new class of key intermediates for natural product synthesis, in good yields

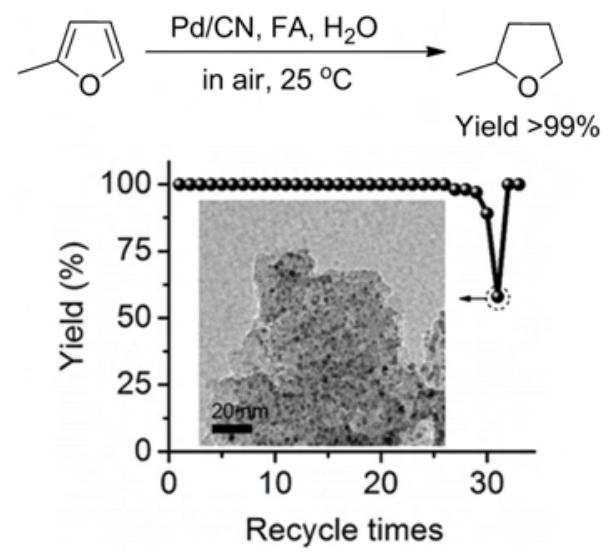

Fig. 2. $\mathrm{Pd} / \mathrm{CN}$-catalyzed hydrogenation of 2-methylfuran and reuse of the Pd/CN catalyst [27].
(78\%-85\%) with FA-Et ${ }_{3} \mathrm{~N}$ using a soluble Pd (0) catalytic system at room temperature. To translate this laboratory method into a cost effective large scale operation, a robust and recyclable Pd catalyst ([Pd0EnCat], Pd NPs $\sim 2 \mathrm{~nm}$ ), that is very efficient for this FA-mediated ketone reduction, was developed by $\mathrm{Yu}$ and co-workers [29] and was used for the reductive ring-opening of benzylic epoxides with $\mathrm{FA}^{-E t_{3} \mathrm{~N}}$ (4 equivalents) under mild conditions $\left(23^{\circ} \mathrm{C}\right)$ via transfer hydrogenolysis. With [Pd0EnCat], the epoxides were opened at the benzylic carbon without any further hydrogenolysis of the alcoholic C-O bond. An excellent isolated yield (97\%) was still obtained after 10 successive recycle runs with trans-stilbene oxide as a model substrate, thus verifying the stability of this catalyst.

As saturated alcohols are considerably more stable than epoxides, an elevated temperature is required for alcohol hydrogenolysis. In the case of the FA-mediated transfer hydrogenolysis of 2-phenyl-2-propanol to isopropylbenzene over supported $\mathrm{Pd}, \mathrm{Pt}$ and $\mathrm{Ru}$ catalysts, $\mathrm{Pd} / \mathrm{C}$ was found the most effective catalyst and FA was much better than formate salts and other agents as a hydrogen donor [30]. Studies investigating the hydrogen-donating ability of the hydrogen source and the effect of the $\mathrm{pH}$ value indicated that the protons in the reaction medium have a promotion effect on this catalytic hydrogenolysis. Under the optimized conditions, excellent selectivity (98.4\%) for isopropylbenzene was achieved at $95.2 \%$ conversion at $80{ }^{\circ} \mathrm{C}$. Other saturated alcohols, including primary, secondary, and tertiary benzylic alcohols, have also been hydrogenolyzed by the Pd/C-FA combination. Very recently, Samec's group [31] developed a very efficient FA-mediated catalytic system using $\mathrm{Pd} / \mathrm{C}$ as the catalyst for the transfer hydrogenolysis of different benzylic alcohols to the corresponding hydrocarbons in moderate to excellent yields (50\%-99\%). An interesting feature was that only catalytic amounts of the added base (5 equivalents relative to palladium) was required to inhibit a competing disproportionation reaction of alcohol to alkane and ketone, allowing the transfer hydrogenolysis to proceed smoothly. Based on the significant primary kinetic isotope effects identified with D-labeled FA, a mechanism was proposed which is shown in Scheme 7. Initially, a formate anion is adsorbed on the low coordinated palladium sites by inhibiting the competing disproportionation. Formate-palladium species were generated, which was followed by reversible proto-

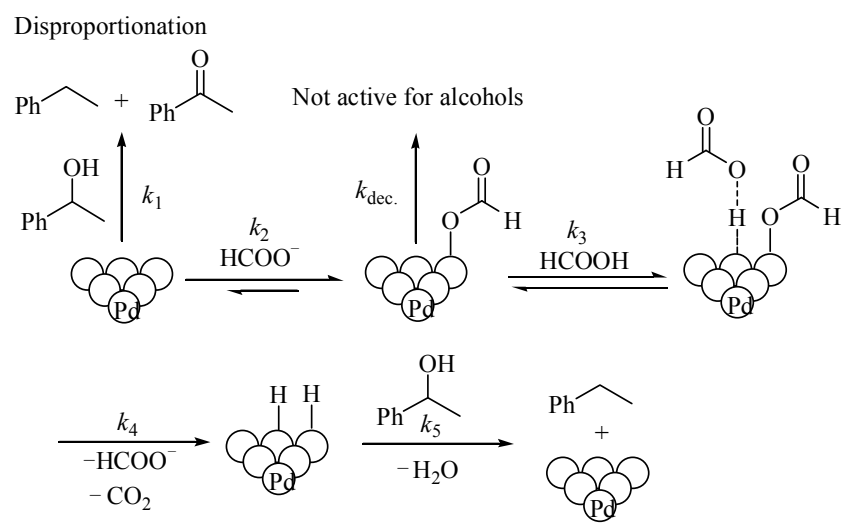

Scheme 7. Reaction mechanism of the transfer hydrogenolysis of 1-phenylethanol by FA [31]. 
nation and a rate determining hydride transfer to generate the active Pd with chemisorbed hydrogen. Finally, the hydrogenolysis of the alcohol was promoted by the chemisorbed hydrogen species to form the corresponding hydrocarbon.

Apart from the catalytic hydrogenolysis of $\mathrm{C}-\mathrm{O}$ bond linkages discussed above, there are also a few reports dealing with the reductive cleavage of $\mathrm{C}-\mathrm{N}$ bonds. On investigating the catalytic hydrogenolysis of tertiary allylic amines, Heck's group [32] reported that the Pd/C-FA-Et 3 N system was useful for selectively removing morpholino and piperidino groups from the tertiary amines. However, the yields for the mixture of two isomeric olefins were moderate $(62 \%-68 \%)$ (Scheme 8). Another interesting FA-mediated hydrogenolysis is deprotection, which is widely utilized for removing a protecting moiety introduced in order to protect a reactive functional group during a series of reactions [33,34]. FA, which is known as a good solvent for most peptides, is now mainly employed for the simple cleavage of benzyl-type protecting groups from peptides as an in situ hydrogen donor. As demonstrated by Gowda [34], benzyl-type protecting groups, including $N^{\alpha}$-benzyloxycarbonyl, $N^{\varepsilon}$-2-chlorobenzyloxycarbonyl, $C$-terminal benzyl ester, $O$-benzyl ether of $O$-benzyltyrosine, serine or threonine, nitro of nitroarginine and $N$ im-benzyloxymethyl of histidine, were successfully removed by a commercially available $10 \% \mathrm{Pd} / \mathrm{C}$ catalyst with FA at $25^{\circ} \mathrm{C}$. In addition, FA-mediated desulfurization and dehydrochlorination, closely connected to the wastewater treatment and fuel industry, have also been investigated with a Pd-based catalyst supported on various minerals [3].

\subsection{Tandem reactions to give complex molecules}

Green and sustainable chemistry necessitates the development of new compact, simple, and reliable technologies and more efficient processes to minimize environmental impacts. In this regard, tandem reactions, also known as cascade or domino reactions, involving flexible FA activation, have been considered as sustainable process intensification strategies to allow access to complex molecules with exceptionally high effi-
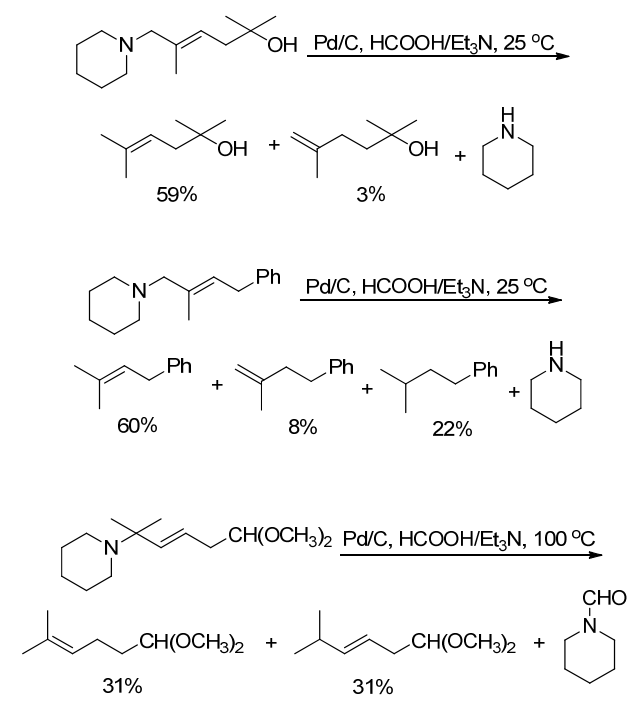

Scheme 8. Hydrogenolysis of tertiary allylicamines with FA [32]. ciency and atom economy. The wide application of FA as a green source for hydrogen described above has encouraged its utilization in simple reductive amination (RA) sequences for the one-step construction of higher amines from a mixture of cheaply available compounds [35]. This is particularly attractive for its step economy as compared to traditional multistep procedures. Meanwhile, FA is also known as a straightforward and convenient source for a formyl group. For example, it is used in the formylation of alcohol under solvent-free and neutral conditions catalyzed by free $\mathrm{I}_{2}$ or $\mathrm{I}_{2}$ generated in situ from $\mathrm{Fe}\left(\mathrm{NO}_{3}\right)_{3} \cdot 9 \mathrm{H}_{2} \mathrm{O} / \mathrm{NaI}$ [36] as well as $\mathrm{N}$-formylation of amines using Amberlite IR-120 [37], $\mathrm{ZnO}$ [38], $\mathrm{CeO}_{2}$ [39] and Natrolite zeolite [40] catalysts. To advance the usage of FA in more complex synthetic systems, Török's group [41] reported a two-step, one-pot domino reaction methodology using $\mathrm{Pd} / \mathrm{C}$ as catalyst with FA both as a reducing and formylating agent to synthesize $\mathrm{N}$-formylindolines and $\mathrm{N}$-formyltetrahydroquinolines (FTHQs), an important class of intermediates for bio-active compounds, by reductive $\mathrm{N}$-formylation of the corresponding indoles and quinolines. However, the pyrophoric nature of the catalyst, high catalyst loading $(10 \mathrm{~mol} \% \mathrm{Pd})$, and the requirement of a large excess of FA (approx. 55 equivalents) have restricted the utility of this procedure.

Very recently, we devised a novel catalytic system capable of the one-pot conversion of quinoline compounds to FTHQs via a reduction-formylation domino reaction sequence utilizing FA as a source of both hydrogen and formyl groups in the presence of supported gold NPs (Scheme 9) [42]. To test the reducing ability of $\mathrm{FA}$, we initially investigated the catalytic selective transfer hydrogenation of quinolines to 1,2,3,4-tetrahydroquinolines (THQs). The gold NPs exhibited far superior catalytic activity and selectivity than those of traditional platinum-group-metal-based catalytic systems. Among the gold catalysts tested, a single phase rutile titania-supported gold $\left(\mathrm{Au} / \mathrm{TiO}_{2}-\mathrm{R}\right)$ with a mean diameter of $2.2 \mathrm{~nm}$ showed the highest activity, affording the THQs in good to excellent yields (from $88 \%$ to $98 \%$ ) under convenient reaction conditions within very short time of $10-50 \mathrm{~min}$, e.g. in a mixed organic solvent (Et ${ }_{3} \mathrm{~N} / \mathrm{DMF}$ in a 1:8 volume ratio) and an appropriate amount of FA (15-45 equivalents) at $130{ }^{\circ} \mathrm{C}$. The solid $\mathrm{Au} / \mathrm{TiO}_{2}-\mathrm{R}$ catalyst can be easily separated from the reaction mixture and reused at least three times without any loss in activity. As a further demonstration of the effectiveness of this system, we found that upon switching the mixed organics to $\mathrm{Et}_{3} \mathrm{~N} / \mathrm{H}_{2} \mathrm{O}$ (3:10) together with 25 equivalents of $\mathrm{FA}, \mathrm{a}$ $\mathrm{Au} / \mathrm{TiO}_{2}-\mathrm{R}$ catalyst was also highly efficient for the tandem synthesis of a diversity of formyl-substituted aromatic $\mathrm{N}$-heterocycles directly from quinolines, isoquinoline and 7,8-benzoquinoline substituted with mono- or dimethyl, halogen, hydroxyl, and methoxy groups in good to excellent yields (from $86 \%$ to $97 \%$ ) at $100{ }^{\circ} \mathrm{C}$. This $\mathrm{FA}$-involved $\mathrm{Au} / \mathrm{TiO}_{2}$ - $\mathrm{R}$ catalytic system was also applicable in a preparative scale reaction, with $10 \mathrm{mmol}$ of isoquinoline successfully formylated to afford valuable $N$-formyltetrahydroisoquinoline in $97 \%$ isolated yield, where the TON reached 3880 . Thus, this new method provides a more cost effective, practical and scalable approach to efficiently access this type of compound. 


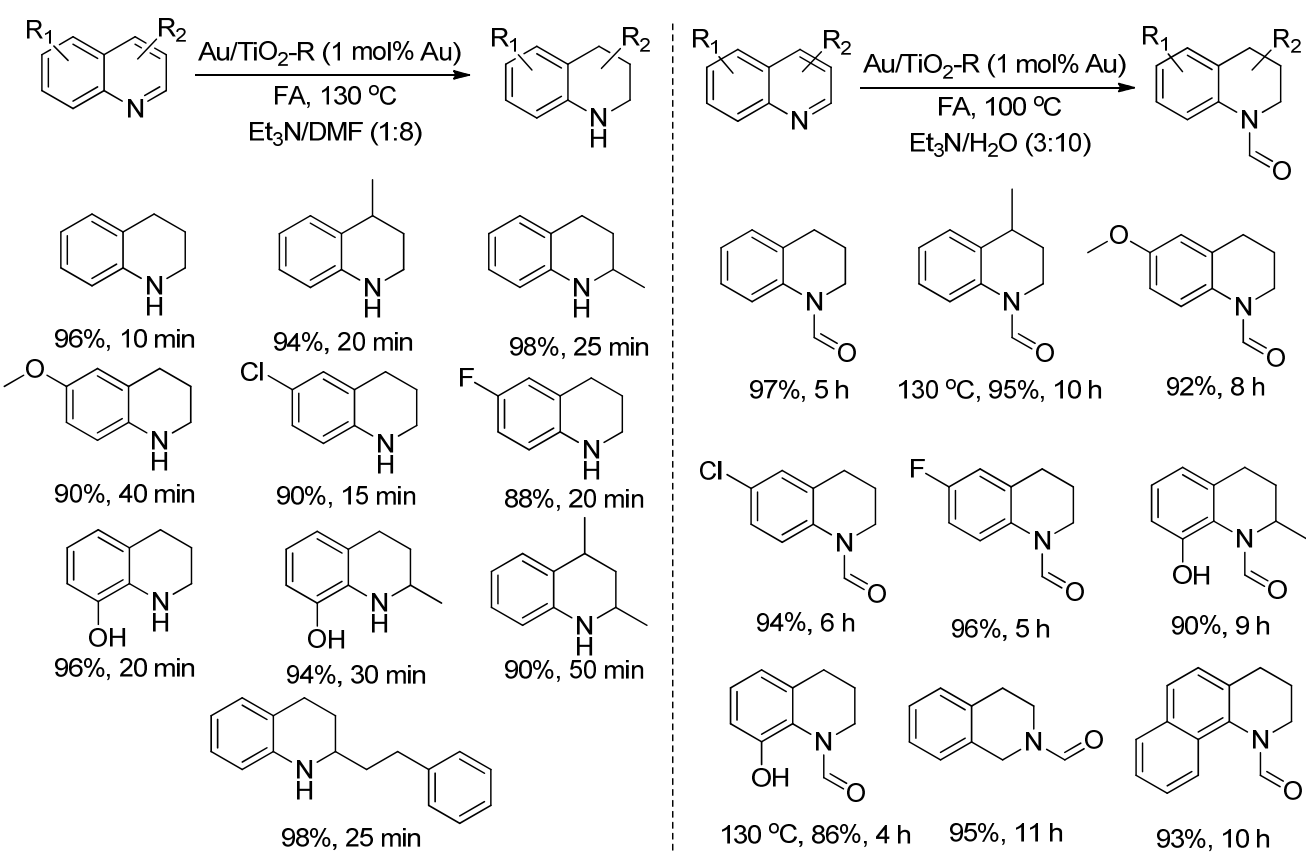

Scheme 9. $\mathrm{Au} / \mathrm{TiO}_{2}$-R-catalyzed reduction or reductive formylation of quinolines [42].

To fully access the valuable chemical diversity and explore the synthetic potential of FA, a general methylation of amine protocol with $\mathrm{Pt}$ complexes (Karstedt's catalyst, $\left.\left[\mathrm{Pt}\left(\mathrm{CH}_{2}=\mathrm{CHSiMe}_{2}\right)_{2} \mathrm{O}\right]\right)$ using $\mathrm{FA}$ as the $\mathrm{C}_{1}$ building block and silanes as the reducing agent was developed by Beller's group [43]. A broad range of amines (more than 35 different amines), including aromatic and aliphatic, and primary and secondary amines, were efficiently converted to their corresponding tertiary amines in good to excellent yields (68\% to 99\%) under mild conditions (r.t. or $60{ }^{\circ} \mathrm{C}$ ). Notably, two $[N-13 \mathrm{C}]$-labelled drugs, $\left[N-{ }^{13} \mathrm{C}\right]$-4-dimethylaminoantipyrine and $\left[N-{ }^{13} \mathrm{C}\right]$-diphenhydramine, were also obtained using $\mathrm{H}^{13} \mathrm{CO}_{2} \mathrm{H}$ as an inexpensive and convenient labelling reagent in $91 \%$ and $85 \%$ yield, respectively (Scheme 10). Following this pioneering study, an improved methodology was further presented by Cantat's group [44] for the direct methylation of amines via a sequential formylation/transfer hydrogenation pathway using FA as a source of carbon and hydrogen. In contrast to the Pt catalytic system, this $\mathrm{Ru}$ (II)-based protocol avoided the use of hydrosilanes as extra sacrificial reductants. However, concerns still remained about the limited selectivity and relatively harsh conditions of this FA-based synthetic strategy. Another attractive example for FA utilization in cascade reactions is the hydroformylation of alkenes using FA as a $\mathrm{C}_{1}$ building block. In 2012, Porcheddu's group [45] developed a Ru-based

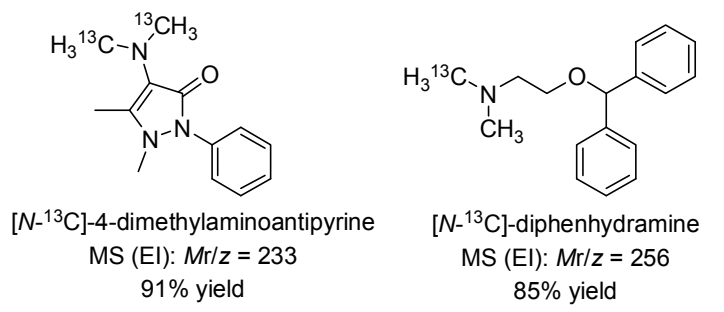

Scheme 10. $\left[{ }^{-13} \mathrm{C}\right]$-labelled drugs synthetized from $\mathrm{H}^{13} \mathrm{CO}_{2} \mathrm{H}$ [43]. two-chamber system to produce a variety of alcohols from alkenes and FA via an oxo-synthesis, where FA decomposed into $\mathrm{CO}_{2}$ and $\mathrm{H}_{2}$ in one chamber and domino RWGS- hydroformylation of alkenes proceeded smoothly in the other chamber (Scheme 11). Along the same vein, FA was also found effective in the direct transformation of alkynes into alcohols or amines via a FA-promoted alkyne-to-ketone hydration coupled with FA-participated transfer hydrogenation and transfer hydrogenative RA in the presence of homogeneous Ir [46] or $\mathrm{Ru}$ [47] catalysts.

\subsection{Disproportionation to methanol}

The works presented above all feature the use of FA as a versatile reagent for fine chemical synthesis. Recently, there were also several reports on the potential of FA as an alternative $\mathrm{C}_{1}$ feedstock to generate basic commodity chemicals, specifically, the selective conversion of FA to methanol, which is an essential bulk chemical and an emerging energy resource with

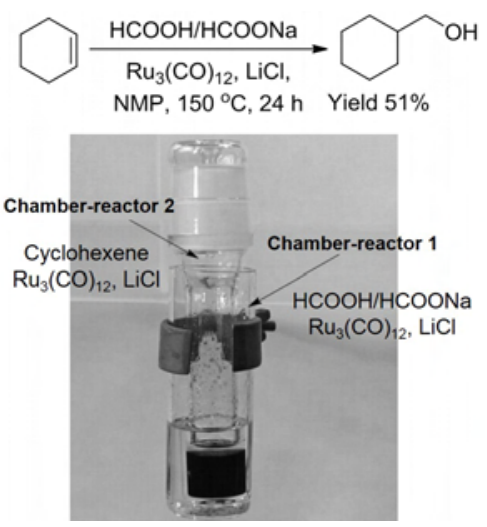

Scheme 11. [ $\left.{ }^{-13} \mathrm{C}\right]$-labelled drugs synthetized from $\mathrm{H}^{13} \mathrm{CO}_{2} \mathrm{H}$ [45]. 
many important industrial uses. Methanol is currently produced from fossil fuels, such as natural gas, coal and oil products (e.g. heavy refinery residues, naphtha). As a result of both the high demand for new reactions that utilize renewable resources and the importance of methanol, a methanol synthesis that fully or partially uses renewable resources is a highly desirable goal. In this context, the direct synthesis of methanol from FA is attractive as it will be a new renewable route to large volume organic chemicals and renewable fuels. Despite this potential, presumably due to perceived problems associated with the unproductive decomposition of FA to produce $\mathrm{CO}_{2} / \mathrm{H}_{2}$ or $\mathrm{CO} / \mathrm{H}_{2} \mathrm{O}$, developing methodologies for direct methanol synthesis from FA has long been neglected. It may be noted, however, that in an early work, Sabatier et al. [9] had already disclosed that some dimethoxymethane was produced in the thermolysis of $\mathrm{FA}$ over $\mathrm{ThO}_{2}$, thereby providing indirect evidence for a methanol producing pathway. In 2013, Miller et al. [10] showed for the first time that it is possible to produce methanol directly by the catalytic disproportionation of FA. A preliminary screening of various molecular iridium species led to the discovery of the well-defined [Cp*Ir-(bpy) $\left.\left(\mathrm{H}_{2} \mathrm{O}\right)\right][\mathrm{OTf}]_{2}$ (1, bpy $=2,2$ '-bipyridine, OTf $=$ trifluoro-methanesulfonate $)$ compound as an effective catalyst for the conversion of FA to $\mathrm{MeOH}$ at $80{ }^{\circ} \mathrm{C}$. One salient feature of this unusual transformation, albeit it is still very limited in overall methanol yield $(<$ $2 \%$ ), is that the reaction can occur smoothly in an acidic aqueous solution ( $3 \mathrm{~mol} / \mathrm{L}, \mathrm{pH}=1.4$ ) without the need for an organic solvent or externally added hydrogen.

A possible hydrogen transfer reaction mechanism for the disproportionation of FA to generate methanol involving the formation of formaldehyde as a central intermediate with FA acting both as hydrogen source and substrate was proposed (Scheme 12) [10]. The first step involves the fast protonolysis of the Ir catalyst by the abstraction of the proton of FA by the basic ligand to generate cationic $\mathrm{Ir}-\mathrm{H}$ complexes. The [Ir-H] ${ }^{+}$ species then undergoes dehydrogenation to give an $\left[\mathrm{Ir}-\mathrm{OH}_{2}\right]^{2+}$ species together with the reduction of protonated FA to give the intermediate formaldehyde (step 2). Subsequent reduction of the resultant formaldehyde by the Ir-H complexes provides methanol (step 3), thereby completing the catalytic cycle. This competing concerted and sequential reaction pathway was well supported by the following experimental results: (i) ${ }^{1} \mathrm{H}$ nuclear magnetic resonance (NMR) and electrospray ionization mass spectrometry (ESI-MS) studies revealed that dissolving precatalyst 1 in $\mathrm{HCO}_{2} \mathrm{H} / \mathrm{D}_{2} \mathrm{O}(3 \mathrm{~mol} / \mathrm{L})$ caused rapid conversion at ambient temperature to a mixture of deuteride

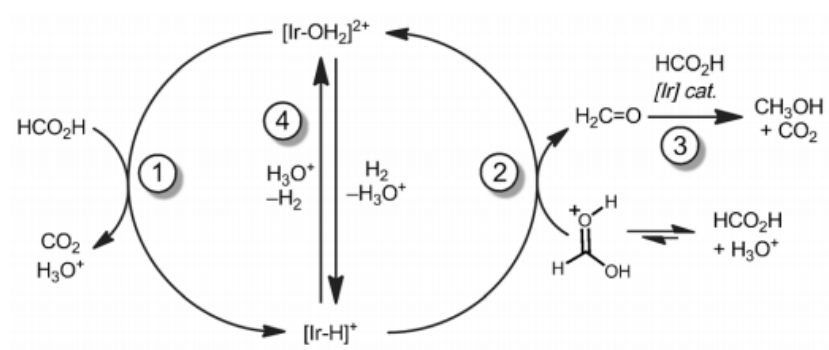

Scheme 12. Proposed pathways for the Ir-catalyzed disproportionation of formic acid to methanol [10].
[Cp*Ir(bpy)D]OTf (2)[10] and the corresponding formate species in an approximately 9:1 ratio; (ii) heating a $\mathrm{HCO}_{2} \mathrm{H} / \mathrm{D}_{2} \mathrm{O}$ solution (3 mol/L) containing ${ }^{13} \mathrm{C}$-enriched paraformaldehyde and 1 to $60{ }^{\circ} \mathrm{C}$ resulted in the rapid formation of ${ }^{13} \mathrm{CH}_{3} \mathrm{OD}$ and ${ }^{13} \mathrm{CH}_{2} \mathrm{DOD}$, with an exceedingly high TOF of $240 \mathrm{~h}^{-1}$ for formaldehyde conversion. It is known that all the iridium complexes tested can form Ir-hydride species in FA disproportionation reactions. The higher disproportionation activity of $\left[\mathrm{Cp}^{*} \mathrm{Ir}-(\mathrm{bpy})\left(\mathrm{H}_{2} \mathrm{O}\right)\right][\mathrm{OTf}]_{2}$ over those other Ir complexes can be attributed to its unique activity for formaldehyde formation (Path $1 \rightarrow 2$ in Scheme 12).

To make the process more attractive in terms of the overall FA-to-MeOH efficiency, a more cost effective catalyst that can improve the selectivity to methanol while keeping the unproductive FA decomposition minimal is preferred. A Ru complex catalyst known to catalyze a wide range of FA-mediated transformations, including FA dehydrogenation and transfer hydrogenation, is one alternative to replace the Ir-based catalyst in this reaction. Ruthenium is far less expensive than iridium ( $\$ 75$ per oz versus $\$ 830$ per oz in 2013). Very recently, Cantat's group [11] demonstrated that using $\mathrm{Ru}$ (II) complexes supported by external phosphine ligands "switch off" the competitive dehydrogenation of FA to $\mathrm{H}_{2}$ and $\mathrm{CO}_{2}$. Specifically, under relatively mild conditions $\left(150^{\circ} \mathrm{C}\right)$ in the presence of $0.6 \mathrm{~mol} \%$ [Ru(COD)(methylallyl) 2$]+$ triphos and $1.5 \mathrm{~mol} \%$ methane-sulfonic acid (MSA), FA was fully decomposed within $1 \mathrm{~h}$ to give $\mathrm{MeOH}$ in $50.2 \%$ yield. In analogy to the above Ir-based systems, the Ru-catalyzed FA disproportionation also appeared to proceed by means of a distinct transfer hydrogenation pathway involving formaldehyde (Scheme 13). Regarding the essential factors that play a role in the desired reaction pathway, one aspect that deserves special mention is that acid promoters such as MSA significantly boosted the catalytic efficiency of [Ru(COD)(methylallyl) 2$]+$ triphos in FA disproportionation. In line with the detailed mechanistic studies investigating the methylation of amines with $\mathrm{CO}_{2} / \mathrm{H}_{2}$ by Beller's [48] and Leitner's group [49], the crucial role of MSA can be attributed to its effectiveness in enabling a facile formation of the reactive $\mathrm{Ru}-\mathrm{H}$ species. While ongoing efforts to optimize the process parameters are necessary for further enhancing $\mathrm{MeOH}$ productivity, one can anticipate that the successful design of a metal catalyst abundant in the Earth with superior selectivity would render the FA-based $\mathrm{C}_{1}$ conversion process a feasible option for renewable $\mathrm{MeOH}$ production.

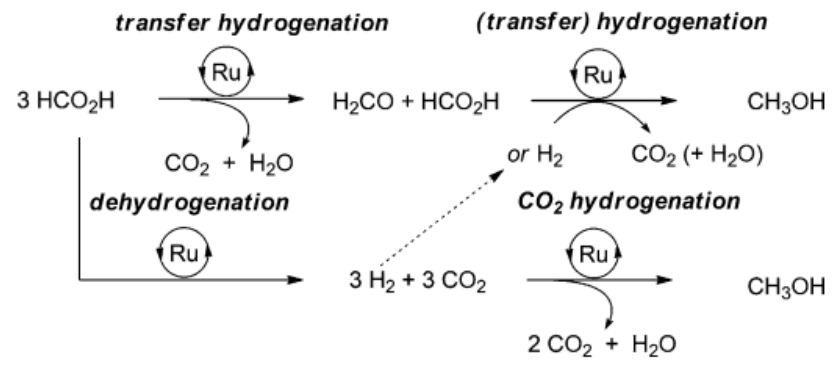

Scheme 13. Pathways for Ru-catalyzed disproportionation of FA to methanol [11]. 


\section{FA-mediated selective biomass valorization}

The preceding section has shown that biogenic FA is a versatile and safe reagent for many useful functional group transformations. The continuing interest in the development of new atom-efficient reactions to afford key chemicals from sustainable resources is one of the central themes in modern chemical research. This driving force has also led to efforts to develop renewable alternatives to diminish the reliance on fossil fuels. Biomass, being a globally distributed resource, can serve as a valuable source for both energy and organic carbon. Due to its renewable nature, it is the only sustainable source of functional compounds for the chemical industry. A further advantage of its chemical production from biomass is the potential to lower greenhouse gas emission because the $\mathrm{CO}_{2}$ released in the conversion process is recycled by the subsequent growth of biomass. The selective conversion of renewable biomass resources into tailor-made products, namely a "bio-refinery", is thus an important and attractive new area of research. By utilizing new green technologies, this envisaged biorefinery would provide a more energy efficient and environmentally sustainable chemical economy. The principle challenge to this advanced bio-based concepts lies in the development of new selective processes to maximize the economic and environmental benefits. A major part of recent research in the field of biorefineries is focused on the exploitation of innovative and economically-viable catalytic methods for the selective transformation of highly functionalized bio-derived feedstocks to value added chemicals and materials. Recent breakthroughs in the development of a number of FA-mediated biomass processing strategies have made this approach more attractive in terms of overall sustainability and resource utilization efficiency.

\subsection{Biomass pretreatment and fractionation}

Lignocellulosic biomass, the most abundant and bio-renewable resource on Earth, is considered one of the most attractive candidates to replace fossil resources for the production of fuel, fuel additives and fine chemicals. A prerequisite of lignocellulose utilization is to fractionate it into its three major components (Fig. 3) [50], namely, cellulose (35\%-50\%), hemicellulose $(20 \%-35 \%)$, and lignin $(10 \%-25 \%)$. For further downstream processing, the degradation of sugars and formation of inhibitors should be avoided or kept to a minimum. Various processes are being pursued globally for lignocellulose pretreatment, including physical, chemical, physicochemical and biological technologies. In this connection, acid pre-hydrolysis is one of the most effective pretreatment methods to disrupt the lignin structure, remove and recover hemicellulose as dissolved sugars, and reduce the crystallinity of cellulose while increasing the porosity of the biomass to facilitate the subsequent bioconversion processes like the enzymatic production of bioethanol. As opposed to the commonly used sulfuric acid, FA is a promising alternative agent to pretreat biomass that does not introduce any additional inorganic salt species, which are potential inhibitors to the downstream heterogeneous or enzymatic catalytic process. FA can be easily

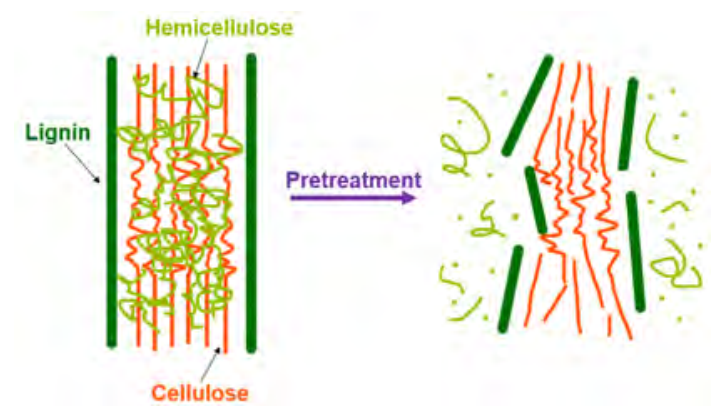

Fig. 3. Schematic of goals of the pretreatment of lignocellulosic material [50].

recycled by distillation due to its low boiling point. For example, Marzialetti et al. [51] recently reported that diluted FA (8\%) can function as an efficient acidic reagent yielding a high dissolution for switchgrass (52 wt\%) at an elevated temperature around $200{ }^{\circ} \mathrm{C}$. This FA-based acid pretreatment achieved a comparable dissolution yield to $\mathrm{H}_{2} \mathrm{SO}_{4}$, while generating less degradation products such as furfural and HMF that cause loss of carbohydrates and inhibition to the subsequent hydrolysis and fermentation steps. Similarly, Xu et al. [52] reported the pretreatment process of corn stover based on in situ formed FA in low concentration, with an overall glucan recovery of $94 \%$ and xylan recovery of $75 \%$ at $195^{\circ} \mathrm{C}$.

Organosolv processes, on the other hand, is also an effective strategy for biomass pretreatment in which the lignocellulosic biomass is treated with a mixture of an organic solvent and water. In contrast to other chemical pretreatments that merely liberate the cellulose fraction for further processing, the main aim of the organosolv process is to fractionate lignocellulose into its individual major fractions, typically recovering relatively pure lignin as a byproduct for the papermaking industry or further valorization. As a readily available and highly biodegradable organic solvent, FA in high concentration has been successfully used in the pulping process and it shows interesting features as an agent for the organosolv fractionation of ligo-cellulosics (Fig. 4). One advantage of this organosolv processes is that a large fraction of lignin dissolves into black liquor with simultaneous hemicellulose degradation into monoand oligosaccharides at good pulp yield, leaving solid cellulose in the residue. In general, effective delignification of the pulp requires a higher concentration ( $>80 \%$ ) of FA. Several approaches for the organosolv fractionation in FA have been reported under quite mild conditions $\left(<130^{\circ} \mathrm{C}\right)$ that give relatively high delignification yields [53-56]. In some studies, FA was combined with catalytic amounts of $\mathrm{H}_{2} \mathrm{O}_{2}$, where the fractionation process relies on the action of in situ generated peroxy FA, which degrades, solubilizes and oxidizes lignin into small fragments. For example, Brosse's group [55] reported that the FA treatment of typha grass with $\mathrm{H}_{2} \mathrm{O}_{2}$ exhibited much better delignification yields than an ethanol organosolv process under microwave conditions. On the other hand, Sun's group [56] showed that the combination of FA and acetic acid provided a more convenient and cost effective way for the fractionation of native biomass such as wheat straw. Thus, by virtue of the FA and acetic acid based organosolv system, FA in 


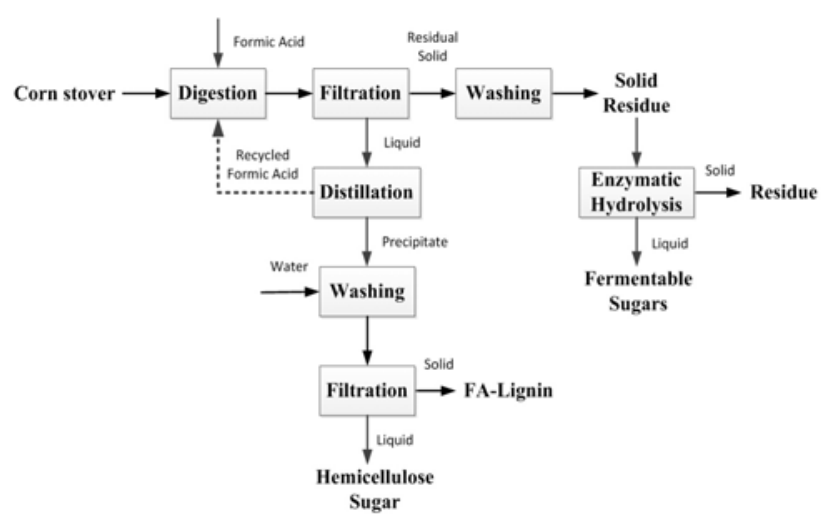

Fig. 4. Flowchart of the fractionation of corn stover by $88 \%$ FA [53].

$20 \%-30 \%$ concentration already gave the best yield of valuable hemicellulose degradation products, especially xylose.

\subsection{Transformation of bio-based platform chemicals}

As a flexible approach for generating tailored renewable compounds, one particularly attractive bio-based strategy is the initial generation of a set of defined platform molecules, which can be used as key intermediates to produce diverse value added chemicals. In this respect, sugars derived from lignocellulose are a very promising class of platform chemicals with versatile applications. The feasibility of a FA-catalyzed biphasic reaction system for sugar dehydration into furan derivatives (HMF and furfural) was evaluated by Hassan's group [57]. As a result of the continuous extraction of furans from the organic methyl-isobutylketone phase, furan formation was enhanced in the aqueous fraction by inhibiting its further conversion into undesired levulinic or formic acid compounds and humins. Moreover, FA was also shown to be an excellent hydrogen donor for the subsequent reduction of $\mathrm{HMF}$ into 2,5-bis(hydroxymethyl)-furan (BHMF) [58] or hydrogenolysis into 1,6-hxanediol [59]. Due to that FA can be an acid catalyst, a solvent, a source of hydrogen and a deoxygenation agent, several multistep one-pot transformations using FA as the main reagent were explored. Rauchfuss's group [60] demonstrated a facile FA-mediated synthesis of liquid fuel 2,5-dimethylfuran (DMF) from fructose, where HMF produced by FA-catalyzed fructose dehydration was first reduced to BHMF with FA in the present of $\mathrm{Pd} / \mathrm{C}$. This was followed by the generation of the targeted DMF by FA-mediated deoxygenation of the diformate ester of BHMF as a result of $\mathrm{H}_{2} \mathrm{SO}_{4}$-asssited BHMF esterification with FA (Scheme 14). In this case, FA provided a milder pathway for DMF synthesis and achieved an excellent yield (> 95\%). The same group also described the production of hybrid fuels from sugars [61], further highlighting the potential utility of FA as both solvent and catalyst for the reactions of fructose, glucose and cellulose. 5-mesitylmenthyfurfural in moderate yields of $20 \%-70 \%$ was obtained by a simple one-pot process comprising sugar dehydration followed by a subsequent Friedel-Crafts arylation of HMF under mild conditions.

Levulinic acid (LA), a versatile platform molecule from the acid catalyzed degradation of biomass, is of interest for the

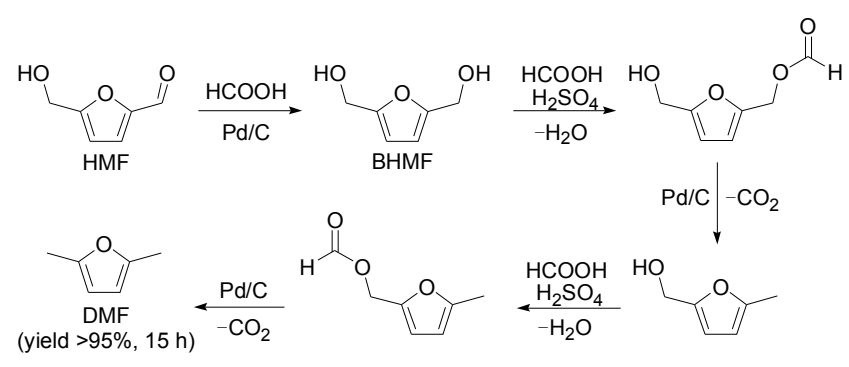

Scheme 14. Pathway to DMF from HMF using FA as reagent [60].

production of many useful $\mathrm{C}_{5}$-based compounds. One key derivatives of LA is $\gamma$-valerolactone (GVL), which was identified as an essential component for the production of both energy and carbon-based consumer products. Given that FA is invariably co-produced in equimolar amount along with LA in the biomass dehydration process, the ideal way for making GVL is the direct use of bio-derived FA as a hydrogen source, which eliminates the need for an external $\mathrm{H}_{2}$ supply and avoids the costly purification of LA (Scheme 15) [65]. However, the implementation of this truly convenient and green approach for making GVL remains challenging, largely due to the lack of readily accessible, applicable and reusable solid catalysts that are sufficiently active and selective for $\mathrm{H}_{2}$ production from FA under the hydrothermal processing conditions. Several relevant studies on the use of homogeneous Ru-based catalysts for the direct synthesis of GVL from LA/FA feeds have been reported [62-64]. We discovered an efficient heterogeneous catalytic system for the direct conversion of bio-derived aqueous LA/FA streams into GVL catalyzed by zirconia supported small $\mathrm{Au}$ nanoparticles $\left(\mathrm{Au} / \mathrm{ZrO}_{2}\right)$ under mild and convenient conditions $\left(150{ }^{\circ} \mathrm{C}\right)$ [65]. The high catalytic performance of the supported Au NPs for in situ generation of $\mathrm{H}_{2}$ gas by selective FA decomposition under mild aqueous conditions is essential. Recently, we further developed a noble metal-free production of GVL from FA/LA streams based on inexpensive copper-based catalysts $\left(\mathrm{Cu} / \mathrm{ZrO}_{2}\right)$ under mild aqueous conditions $\left(160-200{ }^{\circ} \mathrm{C}\right)[66]$. Although these were over 130 times less active in terms of the mass-specific reaction rates $(\mathrm{mmol} /(\mathrm{g} \cdot \mathrm{h})$ ) based on total metal atoms as compared to that of the corresponding $\mathrm{Au} / \mathrm{ZrO}_{2}$ catalytic system under identical reaction conditions, the use of earth abundant copper can be justified by its cost (less than 0.008069 \$/g) and availability.

Glycerol, obtained as a high volume byproduct in the bio-

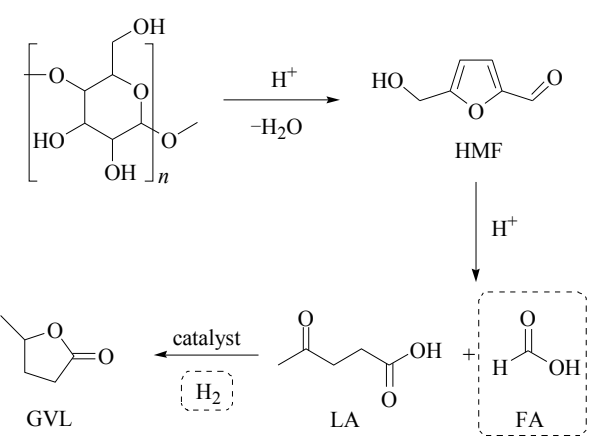

Scheme 15. Catalytic conversion of carbohydrate biomass into GVL [65]. 
diesel process, has also emerged as a promising platform molecule for the production of a variety of value added products. One option for future chemical utilization of glycerol is its conversion to 1,2-propanediol (1,2-PD0) by hydrogenolysis because of the huge market for 1,2-PDO as an industrial solvent, and in the antifreeze and pharmaceutical industries. Gandarias et al. [67] demonstrated that in the absence of externally fed $\mathrm{H}_{2}$, it is possible to produce 1,2-PDO by FA-mediated glycerol hydrogenolysis over a $\mathrm{Ni}-\mathrm{Cu} / \mathrm{Al}_{2} \mathrm{O}_{3}$ catalyst with $90 \%$ glycerol conversion and $82 \%$ selectivity in $24 \mathrm{~h}$ at $220^{\circ} \mathrm{C}$. We have recently contributed to the field of FA-mediated glycerol hydrogenolysis by discovering that $\mathrm{Cu} / \mathrm{ZrO}_{2}$ is more effective for the conversion of glycerol into 1,2-PDO under milder conditions (94\% yield after $18 \mathrm{~h}$ at $200{ }^{\circ} \mathrm{C}$ ) [68]. Consistent with the pathway for the FA-mediated LA-to-GVL process described above, this FA-mediated process does not proceed by a simple transfer hydrogenolysis, but rather by a less straightforward transformation of glycerol with $\mathrm{H}_{2}$ in situ generated from the FA decomposition. Meanwhile, Ellman's group [69] disclosed another FA-mediated didehydroxylation pathway to produce allyl alcohol from glycerol at $240{ }^{\circ} \mathrm{C}$. This reaction proceeded through an orthoester-type intermediate and the further thermal transformation of the cyclic orthoesters finally generates the double bond, as described in the route depicted in Scheme 16. This unexpected route involves the FA-induced direct removal of two hydroxyl groups from glycerol with no hydride transfer process, which is clearly a departure from the conventional FA-mediated dehydration processes via a 1, 2-hydrogen shift pathway followed by reduction. A similar dehydroxylation reaction to synthesize benzoic acid from glucose-derived quinic acid was also reported by the same group [70]. This one-pot, one-reagent deoxygenation of biogenic polyhydroxy compounds with FA will be a valuable alternative for the manufacture of reduced oxygen content products in a biorefinery.

\subsection{Depolymerization and deoxygenation of lignin}

As the most unreactive of the three components of lignocellulosic biomass, lignin has long been treated as a waste product in the pulp and paper industry, where it is burned to supply energy and recover pulping chemicals in the operation of paper mills. The production of higher value compounds from lignin is increasingly recognized as being crucial to the economic viability of integrated biorefineries. The most prominent lignin valorization strategy so far appears to be its depolymerization to generate valuable aromatic chemicals or provide a source of low molecular mass feedstocks for downstream processing. For

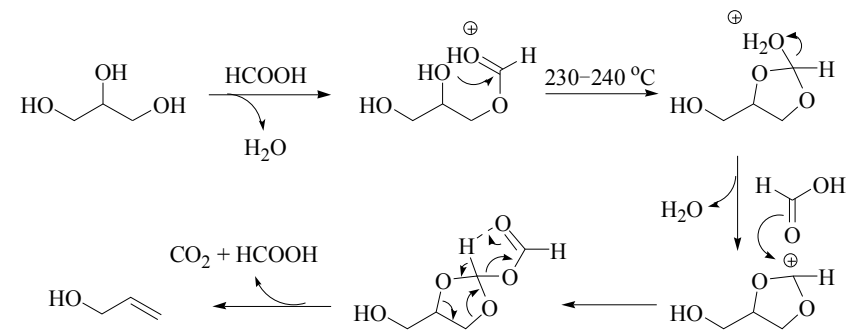

Scheme 16. Mechanism for FA-mediated didehydroxylation [69]. this purpose, sustainable, selective, and catalytic procedures must be developed. Catalytic processes for both oxidative and reductive lignin depolymerization have been reported, although the use of oxidants and/or oxidizing protocols is in principle undesirable because the presence of radicals will lead to the partial re-polymerization of lignin and thus to more complex structures. Results from recent research in this field indicate a general consensus that catalytic reductive methodologies are a valuable approach to maximize the production of phenolic compounds from lignin. To this end, biogenic FA has been identified as a reagent with unique favorable properties compared to $\mathrm{H}_{2}$ gas in facilitating the efficient disassembly of lignin [71-74]. For example, switchgrass lignin can be directly converted into phenolic monomers with a yield of up to $50 \%$ by combining the depolymerization and (hydro)-deoxygenation reactions in a single step [72]. As depicted in Scheme 17, the conversion process involves the thermal treatment of lignin in ethanol or water at $300-350{ }^{\circ} \mathrm{C}$ with $\mathrm{FA}$ as an active hydrogen donor. Upon heating, FA decomposes completely into $\mathrm{CO}_{2}$ and active hydrogen, which combines with oxygen from the methoxy groups of lignin to form water. The presence of a typical hydrodeoxygenation catalyst, $\mathrm{Pt} / \mathrm{C}$, is essential for achieving good results. Since both depolymerization and hydrodeoxygenation occur simultaneously, this splitting reaction can result in monomers with low oxygen contents in a single step.

In the search for new energy-efficient procedures for deconstructing lignin under industrially more favorable conditions, several recent studies showed that FA-mediated catalysis may be of special importance for expedited aromatic extraction under mild and convenient conditions. Owing to the intrinsic unreactive nature of this bulky biomass, most recently developed methods are multistep or require harsh reaction conditions (high hydrogen pressures, temperatures $>350^{\circ} \mathrm{C}$ ). Apart from the prohibitively high capital investment, a major drawback of these procedures is that repolymerization and self-condensation of lignin and its derivatives frequently occur under the processing conditions (due to the formation of radicals and/or $\mathrm{C}-\mathrm{C}$ bonds forming self-condensation reactions in acidic media). This would eventually lead to a complex pool of poorly controlled re-condensed aromatics. It is therefore very significant that Samec and co-workers [75] have found that a simple combination of FA and a heterogeneous palladium catalyst supported on activated charcoal (Pd/C) showed great promise for producing aromatic compounds from lignin under very mild conditions. The method is a mild and robust procedure in which the catalysis is performed at $80{ }^{\circ} \mathrm{C}$ in air without specialized equipment (Scheme 18). This heterogeneous palladium-catalyzed FA-mediated procedure was particular effective for the $\mathrm{C}-\mathrm{O}$ bond cleavage of various lignin models con-

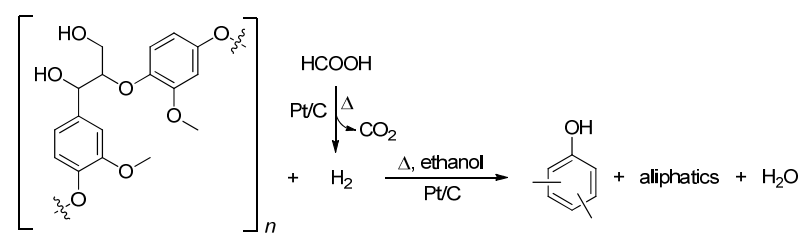

Scheme 17. Lignin depolymerization and hydrodeoxygenation in the presence of FA [72]. 


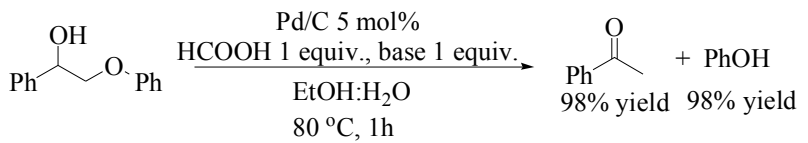

Scheme 18. FA-mediated cleavage of the $\beta-O-4^{\prime}$-ether bond of model lignin compounds [75].

taining the $\beta-O-4$ '-linkage, the most abundant structural motif in lignin. By slightly modifying the reaction conditions, the corresponding aryl ketones and phenols were selectively generated with $>95 \%$ yield even for models having ortho-methoxy substitution in both the 2- and 6-positions of the aryloxy group. Kinetic deuterium labeling experiments supported an initial palladium-catalyzed alcohol dehydrogenation mechanism involving a palladium-formato complex as the key reaction intermediate. Degradation experiments with more challenging pine-derived native lignin, however, afforded only a moderate shift toward lower molecular weight fragments.

As a further demonstration of the possibility of achieving facile $\mathrm{C}-\mathrm{O}$ cleavage for extensive lignin depolymerization, it is worthwhile to mention a recent groundbreaking discovery by the Stahl's group [76] that FA chemistry can be designed for lignin extraction to meet the ultimate goal of producing a significant fraction of higher value mono-aromatic streams for further upgrading (Fig. 5). In contrast to previous procedures, this FA-mediated depolymerization process is notable for its mild conditions with relatively low temperatures $\left(110^{\circ} \mathrm{C}\right)$ and low pressure, as well as the lack of need for expensive metal catalysts. The overall yield (more than $60 \mathrm{wt} \%$ ) of structurally identified, monomeric aromatics obtained by this FA-mediated system was the highest reported so far for lignin depolymerization. Key to this process was the subjecting of oxidized lignin to FA processing, in which the crucial formylation of the oxidized $\beta-O-4$ '-linkage enabling a facile $\mathrm{C}-\mathrm{O}$ cleavage involving subsequent FA elimination from the formyl intermediates was essential. Mechanistically, the beneficial effect of lignin oxidation can be attributed to the ability of the benzylic carbonyl group to polarize the $\mathrm{C}-\mathrm{H}$ bond and lower the barrier for the rate limiting E2 elimination reaction. These observations highlight the importance of developing chemical conversion technology for S-, G- and H-derived aromatics and suggest that plants containing lignin with high $\beta-0-4$ content (as much as $85 \%$ has been observed) can be feedstocks for biomass valorization. Of significant practical importance is that there is no net con- sumption of FA during the process of aromatic production, thus opening up a new redox-neutral pathway for lignin valorization to bulk chemicals. This feature distinguishes this approach from reported lignin conversion methods that employ FA as a source of $\mathrm{H}_{2}$ in transfer hydrogenation/hydrogenolysis reactions with heterogeneous catalysts. The high efficiency of this redox-neutral process, operating under mild ambient conditions, exemplifies once more the unique opportunities offered by FA-mediated biorefining.

\subsection{Upgrading of bio-oil and related model compounds}

Within the frame of second generation biorefinery development, bio-oil derived from fast pyrolysis has emerged as a viable choice for making liquid fuels and chemicals from lignocellulosic biomass. Unfortunately, owing to its high oxygen content and instability, the direct use of bio-oil as a transportation fuel is not feasible. A promising route to improve the properties of bio-oil is the removal of oxygenated groups by a catalytic hydrotreatment called hydrodeoxygenation (HDO). However, the use of petrochemically-derived $\mathrm{H}_{2}$ gas may not be economically suitable and it also poses safety concerns. As a result, a method that can reduce and even eliminate the external $\mathrm{H}_{2}$ consumption is of great fundamental and practical interest. Several efforts have been directed to refine bio-oil by in situ hydrogen generated in aqueous phase reforming (APR), while most of these previously reported methods suffer from problems like low product quality and/or the necessity of a prolonged operation. Thus, the development of refining methods with more convenient reagents, simpler procedures and higher HDO efficiency is highly desired. As with the case with many of the conversions of various forms of bio-derived feedstocks, one can also envision that the FA-mediated reductive strategy can afford a green, efficient and cost effective protocol for bio-oil upgrading under HDO conditions, since FA is increasingly accepted as a carbon neutral, renewable and readily available hydrogen source. Xiong and co-workers [77] conceptually demonstrated that for the processing of crude bio-oil in methanol with liquid FA, the properties of the liquid product can be significantly improved (Fig. 6). Among the catalysts investigated, $\mathrm{Ru}$ was more effective than $\mathrm{Pd}$ and $\mathrm{Ni}$ based catalysts. Furthermore, the reaction routes of the main components showed that the partial hydrogenation was achieved without coke or tar formation. There was no obvious deep reduction

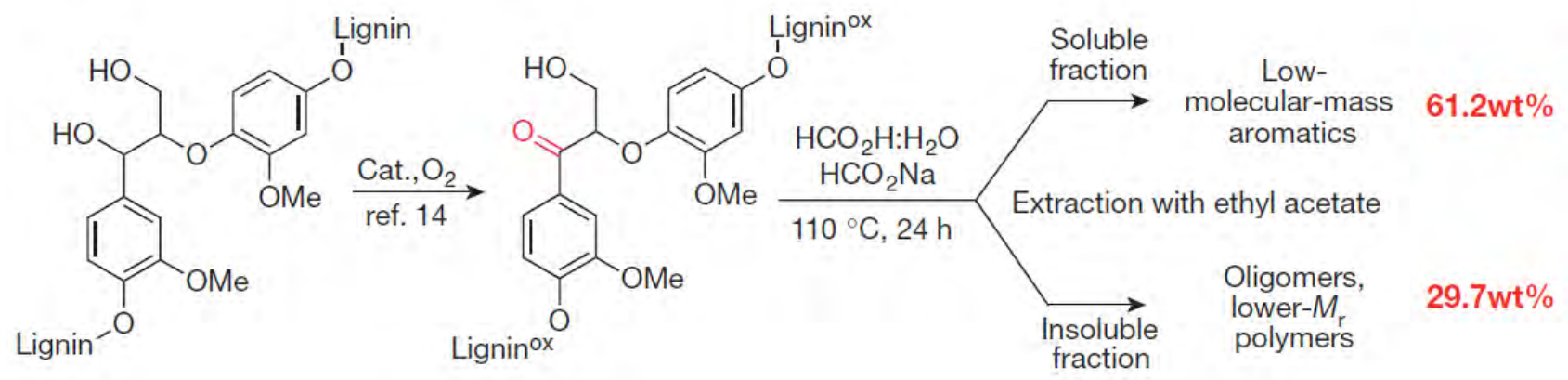

Fig. 5. Depolymerization of aspen lignin with FA [76]. 
that took place, yet the compounds containing alkenyl or aldehyde groups were almost completely reduced.

Preliminary efforts are also devoted to FA-mediated upgrading of bio-oil model compounds, such as phenolic monomers and furans, with the aim to understand the requirements of this type of biorefining and the mechanisms. It should also be mentioned that, although many Group VIII and IB metals, notably palladium and gold, have been shown to facilitate FA dehydrogenation, the high cost and scarcity of these metals make the relevant systems difficult for practical implementation. Huge challenges but also opportunities are present for developing less expensive metal catalysts that are stable and active for FA-mediated biorefining. In a recently published study focusing on the HDO of phenol and furfural by in situ $\mathrm{H}_{2}$ generated from FA, Zhang's group [78] reported that commercial Pd/C and Ni-based catalysts can give the corresponding hydrogenated products. The experiments were performed in a batch reactor at the relatively mild temperature of $300{ }^{\circ} \mathrm{C}$. The HDO efficiency depended strongly on the type of catalyst used. Taking the case of FA-mediated phenol deoxygenation for example, very poor results were obtained for $\mathrm{Pd} / \mathrm{C}$ as compared to the Ni-based catalyst, despite its notably higher ability to promote selective FA dehydrogenation. This was mostly due to the lack of sufficient catalytic hydrogenation activity under the described conditions. Most recently, the utilization of vanillin (4-hydroxy-3-methoxybenzaldehyde) as a model compound in the FA-mediated biorefining was studied by Xiao and co-workers [79]. Benefiting from the dual presence of $\mathrm{Pd} / \mathrm{TiO}_{2}$ sites for FA dehydrogenation and $\mathrm{Pd} / \mathrm{N}-\mathrm{C}$ sites for vanillin hydrogenation, a bifunctional Pd/TiO $@$ @N-C catalyst prepared by supporting Pd NPs onto a composite support comprising $\mathrm{TiO}_{2}$ and nitrogen-modified porous carbon achieved the full hydrogenation of vanillin into 2-methoxy-4-methyl-phenol (MMP) as the sole product. Such synergy of individual catalytic phases can open an alternative route for designing and developing catalysts for future bio-oil upgrading.

\section{Conclusions and outlook}

This review described recent efforts on green chemical reactions and processes based on the use of biogenic FA as a reagent. Many chemical transformations based on renewable feedstocks have been developed in response to the demand for

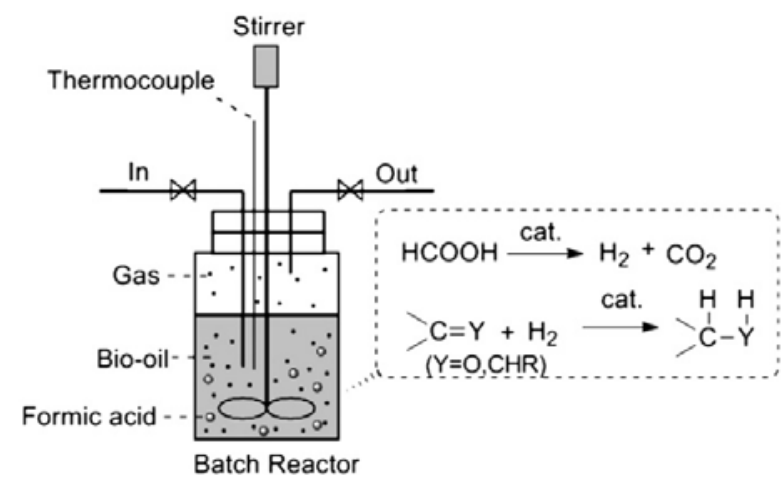

Fig. 6. Bio-oil hydroprocessing using FA as in situ hydrogen source [77]. more benign chemical syntheses. This development promoted the use of FA because of its unique properties as described in this review. As illustrated by a variety of transformations, FA is a powerful and versatile reagent building block for sustainable organic synthesis. Of specific interest to modern industry is the carbon-neutral production of many bio-renewable chemicals achieved by the development of new FA-mediated catalytic process concepts for the integrated valorization of biomass resources. Although much progress has been made in the past few years, more research needs to be conducted in the area of FA-mediated catalysis. Given the high demands of the modern industry for environment, economy and sustainable development, green and affordable FA-mediated processes have great potential and significance for developing sustainable solutions, especially when the following aspects can be realized: (1) select and exploit the appropriate catalytic material containing a suitable active metal species for useful catalytic reactions; (2) controllably activate FA in the presence of other reactants and reagents; (3) understand the mechanism of the complex reactions that take place, and (4) stabilize the catalyst during the catalytic reaction process. It is expected that FA-based chemistry, particularly FA-mediated catalytic transformations, will be of increasing scientific and engineering interest in the coming years.

\section{References}

[1] Kamm B, Gruber P R, Kamm M. Biorefineries-Industrial Processes and Products: Status Quo and Future Directions. Vol. 1. Weinheim: Wiley-VCH, 2006.

[2] Grasemann M, Laurenczy G. Energy Environ Sci, 2012, 5: 8171

[3] Nishimura S. Handbook of Heterogeneous Catalytic Hydrogenation for Organic Synthesis. Chichester: Wiley, 2001.

[4] Blaser H U, Malan C, Pugin B, Spindler F, Steiner H, Studer M. Adv Synth Catal, 2003, 345: 103

[5] Wang W F, Zhang Y F, Li J Q, Ding K N. Chin J Catal (王文峰, 章永 凡, 李俊篯, 丁开宁. 催化学报), 2004, 25: 129

[6] Chen T, Wu G P, Feng Z C, Hu G S, Su W G, Ying P L, Li C. Chin J Catal (陈涛, 吴国鹏, 冯兆池, 胡庚申, 苏伟光, 应品良, 李灿. 催化学 报), 2008, 29: 105

[7] Ertl G, Knözinger H, Schüth F, Weitkamp J. Handbook of Heterogeneous Catalysis. 2nd Ed. Weinheim: Wiley-VCH, 2008.

[8] Gibson H W. Chem Rev, 1969, 69: 673

[9] Sabatier P, Mailhe A. Compt Rend, 1911, 152: 1044

[10] Miller A J M, Heinekey D M, Mayer J M, Goldberg K I. Angew Chem Int Ed, 2013, 52: 3981

[11] Savourey S, Lefèvre G, Berthet J-C, Thuéry P, Genre C, Cantat T. Angew Chem Int Ed, 2014, 53: 10466

[12] Gladiali S, Alberico E. Chem Soc Rev, 2006, 35: 226

[13] Talwar D, Wu X F, Saidi O, Salguero N P, Xiao J L. Chem Eur J, 2014, 20: 12835

[14] Wienhöfer G, Westerhaus F A, Junge K, Beller M. J Organomet Chem, 2013, 744: 156

[15] Mizugaki T, Kanayama Y, Ebitani K, Kaneda K. J Org Chem, 1998, 63: 2378

[16] Liu P N, Gu P M, Deng J G, Tu Y Q, Ma Y P. Eur J Org Chem, 2005: 3221

[17] Li J, Zhang Y M, Han D F, Gao Q, Li C.J Mol Catal A, 2009, 298: 31

[18] Yu J Q, Wu H C, Ramarao C, Spencer J B, Ley S V. Chem Commun, 2003: 678 


\section{Graphical Abstract}

Chin. J. Catal., 2015, 36: 1461-1475 doi: 10.1016/S1872-2067(15)60861-0

Formic acid: A versatile renewable reagent for green and sustainable chemical synthesis

Xiang Liu, Shushuang Li, Yongmei Liu, Yong Cao*

Fudan University

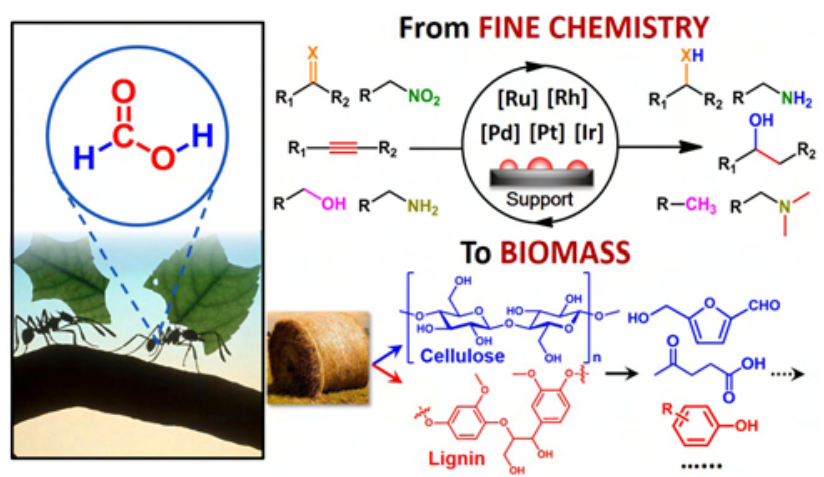

Despite its structural simplicity, formic acid is a versatile bio-renewable feedstock for opening up new chemical space to lead to the discovery of new sustainable reactions of unprecedented selectivity.

[19] Vilches-Herrera M, Werkmeister S, Junge K, Börner A, Beller M. Catal Sci Technol, 2014, 4: 629

[20] Banerjee A A, Mukesh D.J Chem Soc, Chem Commun, 1988: 1275

[21] Jouannin C, Dez I, Gaumont A C, Taulemesse J M, Vincent T, Guibal E. Appl Catal B, 2011, 103: 444

[22] Tuteja J, Nishimura S, Ebitani K. RSC Adv, 2014, 4: 38241

[23] Jagadeesh R V, Banerjee D, Arockiam P B, Junge H, Junge K, Pohl M-M, Radnik J, Brückner A, Beller M. Green Chem, 2015,17: 898

[24] Yu J Q, Spencer J B. Chem Commun, 1998: 1935

[25] Wagh Y S, Asao N. J Org Chem, 2015, 80: 847

[26] Bulushev D A, Ross J R H. Catal Today, 2011, 163: 42

[27] Gong L H, Cai Y Y, Li X H, Zhang Y N, Su J, Chen J S. Green Chem, 2014, 16: 3746

[28] Shimizu I, Oshima M, Nisar M, Tsuji J. Chem Lett, 1986: 1775

[29] Ley S V, Mitchell C, Pears D, Ramarao C, Yu J Q, Zhou W Z. Org Lett, 2003, 5: 4665

[30] Liu X H, Lu G Z, Guo Y L, Guo Y, Wang Y S, Wang X H. J Mol Catal A, 2006, 252: 176

[31] Sawadjoon S, Lundstedt A, Samec J S M. ACS Catal, 2013, 3: 635

[32] Weir J R, Patel B A, Heck R F. J Org Chem, 1980, 45: 4926

[33] Elamin B, Anantharamaiah G M, Royer G P, Means G. J Org Chem, 1979, 44: 3442

[34] Gowda D C. Indian J Chem B, 2002, 41: 1064

[35] Wang C, Pettman A, Bacsa J, Xiao J L. Angew Chem Int Ed, 2010, 49 7548

[36] Amin R, Ardeshir K, Heider Ali A N, Zahra T R. Chin J Catal (催化学 报), 2011, 32: 60

[37] Muthukur Bhojegowd M R, Nizam A, Pasha M A. Chin J Catal (催化 学报), 2010, 31: 518

[38] Sajadi S M, Maham M, Rezaei A. Lett Org Chem, 2014, 11: 49

[39] Hosseini-Sarvari M, Sharghi H.J Org Chem, 2006, 71: 6652

[40] Habibi D, Nasrollahzadeh M, Sahebekhtiari H. J Mol Catal A, 2013, 378: 148

[41] Kulkarni A, Gianatassio R, Török B. Synthesis, 2011: 1227

[42] Tao L, Zhang Q, Li S S, Liu X, Liu Y M, Cao Y. Adv Synth Catal, 2015, 357: 753

[43] Sorribes I, Junge K, Beller M. Chem Eur J, 2014, 20: 7878
[44] Savourey S, Lefèvre G, Berthet J-C, Cantat T. Chem Commun, 2014, 50: 14033

[45] Mura M G, De Luca L, Giacomelli G, Porcheddu A, Adv Synth Catal, 2012, 354: 3180

[46] Li J, Wang C, Xue D, Wei Y W, Xiao J L. Green Chem, 2013, 15: 2685

[47] Zeng M S, Li L, Herzon S B. J Am Chem Soc, 2014, 136: 7058

[48] Li Y H, Sorribes I, Yan T, Junge K, Beller M. Angew Chem Int Ed, 2013, 52: 12156

[49] Beydoun K, vom Stein T, Klankermayer J, Leitner W. Angew Chem Int Ed, 2013, 52: 9554

[50] Hsu T A, Ladisch M R, Tsao G T. Chem Technol, 1980, 10: 315

[51] Marzialetti T, Miller S J, Jones C W, Agrawal P K. J Chem Technol Biotechnol, 2011, 86: 706

[52] Xu J, Thomsen M H, Thomsen A B. J Microbiol Biotechnol, 2009, 19: 845

[53] Yu G, Li B, Liu C, Zhang Y D, Wang H S, Mu X D. Ind Eng Chem Res, 2013, 50: 750

[54] Jahan M S, Chowdhunry D A N, Islam M K. Ind Crops Prod, 2007, 26: 324

[55] Abeywickrama C J, Timilsena Y P, Rakshit S K, Chrusciel L, Brosse N. Ind Eng Chem Res, 2013, 52: 1691

[56] Xu F, Liu C F, Geng Z C, Sun J X, Sun R C, Hei B H, Lin L, Wu S B, Je J. Polym Degrad Stab, 2006, 91: 1880

[57] Abou-Yousef H, Hassan E B. Fuel, 2014, 137: 115

[58] Thananatthanachon T, Rauchfuss T B. ChemSusChem, 2010, 3: 1139

[59] Tuteja J, Choudhary H, Nishimura S, Ebitani K. ChemSusChem, 2014, 7: 96

[60] Thananatthanachon T, Rauchfuss T B. Angew Chem Int Ed, 2010, 49: 6616

[61] Zhou XY, Rauchfuss T B. ChemSusChem, 2013, 6: 383

[62] Deng L, Li J, Lai D M, Fu Y, Guo Q X. Angew Chem Int Ed, 2009, 48: 6529

[63] Deng L, Zhao Y, Li J, Fu Y, Liao B, Guo Q X. ChemSusChem, 2010, 3: 1172

[64] Braden D J, Henao C A, Heltzel J, Maravelias C C, Dumesic J A. Green Chem, 2011, 13: 1755 
[65] Du X L, He L, Zhao S, Liu Y M, Cao Y, He H Y, Fan K N. Angew Chem Int Ed, 2011, 50: 7815

[66] Yuan J, Li S S, Yu L, Liu Y M, Cao Y, He H Y, Fan K N. Energy Environ Sci, 2013, 6: 3308

[67] Gandarias I, Requies J, Arias P L, Armbruster U, Martin A. J Catal, 2012, 290: 79

[68] Yuan J, Li S S, Yu L, Liu Y M, Cao Y. Chin J Catal (袁静, 李舒爽, 于 否, 刘永梅, 曹勇. 催化学报), 2013, 34: 2066

[69] Arceo E, Marsden P, Bergman R G, Ellman J A. Chem Commun: 2009, (23): 3357

[70] Arceo E, Ellman J A, Bergman R G. ChemSusChem, 2010, 3: 811

[71] Huang S H, Mahmood N, Tymchyshyn M, Yuan Z S, Xu C B. Bioresour Technol, 2014, 171: 95

[72] Xu W Y, Miller S J, Agrawal P K, Jones C W. ChemSusChem, 2012, 5:
667

[73] Toledano A, Serrano L, Balu A M, Luque R, Pineda A, Labidi J. ChemSusChem, 2013, 6: 529

[74] Forchheim D, Gasson J R, Hornung U, Kruse A, Barth T. Ind Eng Chem Res, 2012, 51: 15053

[75] Galkin M V, Sawadjoon S, Rohde V, Dawange M, Samec J S M. ChemCatChem, 2014, 6:179

[76] Rahimi A, Ulbrich A, Coon J J, Stahl S S. Nature, 2014, 515: 249

[77] Xiong W M, Fu Y, Zeng F X, Guo Q X. Fuel Process Technol, 2011, 92: 1599

[78] Tan Z C, Xu X M, Liu Y G, Zhang C S, Zhai Y P, Peng L, Li Y, Zhang R Q. Environ Prog Sustain Energy, 2014, 33: 751

[79] Wang L, Zhang B S, Meng X J, Su D S, Xiao F S. ChemSusChem, 2014, 7: 1537

\title{
利用多功能、多用途的可再生甲酸实现化学品的绿色与可持续合成 \\ 柳 翔”，李舒爽 ${ }^{\dagger}$, 刘永梅, 曹 勇 ${ }^{*}$ \\ 复旦大学化学系, 上海市分子催化和功能材料重点实验室, 上海200433
}

\begin{abstract}
摘要: 近年来,随着化石资源日趋短缺以及由此带来的人类生存环境日益恶化,生物质等可再生资源的高效、可持续利用已成为各 国科学家研究与关注的焦点. 甲酸,生物精炼中的主要副产物之一, 具备廉价易得、无毒、能量密度高以及可再生可降解等特性, 将 其应用于新能源利用与化学转化, 不仅有助于甲酸应用领域的进一步拓展,还有助于解决面向未来的生物精炼技术中的一些共性 瓶颈问题. 本文简要回顾了甲酸利用的研究历史, 总结了甲酸作为高效、多用途试剂与原料在化学品合成及生物质催化转化等方 面的最新研究进展, 并对利用甲酸活化来实现高效化学转化的基本原理及催化体系进行了对比分析, 指出今后研究重点应着眼于 努力提高甲酸的利用效率,同时实现高选择性合成两方面,并在此基础上进一步拓展其应用领域.

在化学品合成方面, 甲酸作为一种环境友好可再生的多功能试剂可应用于多种官能团的选择转化过程. 作为一种高含氢量的 氢转移试剂或还原剂, 甲酸相较传统氢气具有操作简便可控、条件温和、具有良好化学选择性等优点,广泛应用于醛酮、硝基、 亚胺、腈、炔烃、烯烃等的选择还原以制取相应的醇、胺、烯烃和烷烃类化合物, 以及醇类和环氧化物的氢解和官能团去保护等 过程. 鉴于甲酸亦可用作 $\mathrm{C}_{1}$ 原料, 作为多用途的关键基础试剂甲酸还可应用于包括喹啉衍生物的还原甲酰化、胺类化合物甲酰化 和甲基化, 烯烃羰化以及炔烃还原水合等多级串联反应, 是实现精细复杂有机分子高效简约绿色合成的重要途径. 该类过程的挑 战在于寻求对甲酸及特定官能团的可控活化兼具高选择性和高活性的多功能催化剂. 此外, 近期有研究表明以甲酸为 $\mathrm{C}_{1}$ 原料还可 通过催化歧化反应直接高选择性合成甲醇等大宗化学品.

在生物质催化转化方面, 甲酸的多功能特性为实现绿色、安全、高原子经济性生物精炼过程提供了潜在可能. 生物质资源是 储量最大、最具潜力的可持续替代资源,但将其转化为可利用的资源形式仍然面临挑战. 甲酸的酸性质及良好溶剂特性可应用于 生物质原料预处理过程, 实现木质纤维素组分分离和纤维素提取, 相较传统无机酸预处理体系具有沸点低、易分离、不引入无机 离子、对下游反应兼容性强等优点; 而作为高效氢源, 甲酸也被广泛研究应用于生物质平台化合物选择催化转化制高附加值化学 品、木质素降解制芳烃化合物和生物油加氢脱氧精制处理等过程, 相较依赖 $\mathrm{H}_{2}$ 的传统氢化过程具有转化效率高、反应条件温和, 简 便安全并可有效减少相关生物精炼过程中化石资源的物耗与能耗等优势. 最新研究表明,通过在温和条件下甲酸水溶液中解聚氧 化木质素, 可得到重量比大于 $60 \%$ 的低分子量芳烃溶液, 这一创新性发现为从木质素中直接提取高值芳香化学物等化学品带来了 新的机遇.

综上所述,生物基甲酸在绿色有机合成和生物质转化等方面表现出巨大潜力,而其多功能性和多用途性对于实现原料的高效 利用及目标产物的高选择性至关重要. 该领域目前已取得了一定成果并得到了快速发展, 然而距实际产业应用还有相当距离, 需 要进一步探索. 今后的研究重点应着眼于以下几个方面: (1)如何针对特定反应优选合适的催化活性金属及反应体系; (2)如何在其 他原料和试剂存在条件下高效、可控地活化甲酸; (3)如何从分子层面理解复杂反应的反应机制; (4)如何在相关过程中稳定相应催 化剂. 展望未来,基于现代社会对环境、经济和可持续发展的需求, 甲酸化学将得到产业界与学术界越来越多的关注和研究.
\end{abstract}

关键词: 甲酸; 新型催化; 可再生氢能源; 环境友好型试剂; 化学合成; 生物精炼

收稿日期: 2015-03-02. 接受日期: 2015-04-04. 出版日期: 2015-09-20.

“通讯联系人. 电话: (021)55665287; 传真: (021)65643774; 电子信箱: yongcao@fudan.edu.cn

†共同第一作者.

基金来源：国家自然科学基金(21273044，21473035); 博士点基金(20120071110011); 上海市科学技术委员会资助项目 (08DZ2270500, 12ZR1401500).

本文的英文电子版由Elsevier出版社在ScienceDirect上出版(http://www.sciencedirect.com/science/journal/18722067). 